\title{
The iron-responsive microsomal proteome of Aspergillus fumigatus
}

\author{
Nicola M. Moloney ${ }^{\mathrm{a}, 1}$, Rebecca A. Owens ${ }^{\mathrm{a}, 1}$, Paula Meleady ${ }^{\mathrm{b}}$, Michael Henry ${ }^{\mathrm{b}}$, Stephen K. Dolan ${ }^{\mathrm{a}}$, \\ Eoin Mulvihill ${ }^{\mathrm{a}}$, Martin Clynes ${ }^{\mathrm{b}}$, Sean Doyle ${ }^{\mathrm{a}, *}$ \\ a Department of Biology, Maynooth University, Maynooth, Co. Kildare, Ireland \\ b The National Institute for Cellular Biotechnology, Dublin City University, Glasnevin, Dublin 9, Ireland
}

\section{A R T I C L E I N F O}

Article history:

Received 9 October 2015

Received in revised form 2 December 2015

Accepted 23 December 2015

Available online 29 December 2015

\section{Keywords:}

Iron

Aspergillus fumigatus

Fungal proteomics

Siderophore

Membrane proteins

\begin{abstract}
A B S T R A C T
Aspergillus fumigatus is an opportunistic fungal pathogen. Siderophore biosynthesis and iron acquisition are essential for virulence. Yet, limited data exist with respect to the adaptive nature of the fungal microsomal proteome under iron-limiting growth conditions, as encountered during host infection. Here, we demonstrate that under siderophore biosynthetic conditions - significantly elevated fusarinine C (FSC) and triacetylfusarinine C (TAFC) production $(p<0.0001)$, extensive microsomal proteome remodelling occurs. Specifically, a four-fold enrichment of transmembrane-containing proteins was observed with respect to whole cell lysates following ultracentrifugation-based microsomal extraction. Comparative label-free proteomic analysis of microsomal extracts, isolated following iron-replete and -deplete growth, identified 710 unique proteins. Scatterplot analysis (MaxQuant) demonstrated high correlation amongst biological replicates from each growth condition (Pearson correlation $>0.96$ within groups; biological replicates $(n=4)$ ). Quantitative and qualitative comparison revealed 231 proteins with a significant change in abundance between the iron-replete and iron-deplete conditions ( $p<0.05$, fold change $\geq 2$ ), with 96 proteins showing increased abundance and 135 with decreased abundance following iron limitation, including predicted siderophore transporters. Fluorescently labelled FSC was only sequestered following A. fumigatus growth under iron-limiting conditions. Interestingly, human sera exhibited significantly increased reactivity $(p<0.0001)$ against microsomal protein extracts obtained following iron-deplete growth.

Biological significance: The opportunistic fungal pathogen Aspergillus fumigatus must acquire iron to facilitate growth and pathogenicity. Iron-chelating non-ribosomal peptides, termed siderophores, mediate iron uptake via membrane-localised transporter proteins. Here we demonstrate for the first time that growth of $A$. fumigatus under iron-deplete conditions, concomitant with siderophore biosynthesis, leads to an extensive remodelling of the microsomal proteome which includes significantly altered levels of 231 constituent proteins (96 increased and 135 decreased in abundance), many of which have not previously been localised to the microsome. We also demonstrate the first synthesis of a fluorescent version of fusarinine $C$, an extracellular A. fumigatus siderophore, and its uptake and localization under iron-restricted conditions. This infers the use of an $A$. fumigatus siderophore as a 'Trojan horse' to potentiate the efficacy of anti-fungal drugs. Finally, in addition to revealing the Aspergillus-specific IgG reactivity in normal human sera against microsomal proteins, there appears to be a significantly increased reactivity against microsomal proteins obtained following iron-restricted growth. We hypothesise that iron-limiting environment in humans, which has evolved to nutritionally limit pathogen growth in vivo, may also alter the fungal microsomal proteome.
\end{abstract}

(c) 2016 Elsevier B.V. All rights reserved.

\section{Introduction}

Consequent to its role in many biological processes, iron is an indispensible element for the majority of prokaryotes and all

\footnotetext{
* Corresponding author at: Department of Biology, Maynooth University, Maynooth, Co. Kildare, Ireland.

E-mail address: sean.doyle@nuim.ie (S. Doyle).

URL: https://www.maynoothuniversity.ie/biology (S. Doyle).

${ }^{1}$ Joint first authors.
}

eukaryotes. The ability of iron to cycle between two oxidative states, ferrous $\left(\mathrm{Fe}^{2+}\right)$ and ferric $\left(\mathrm{Fe}^{3+}\right)$, makes it an ideal catalyst for metabolic reactions and cofactor for many proteins. However, excess iron can mediate toxicity via the Haber-Weiss-Fenton sequence [1]. Consequently, iron homeostasis must be a tightly managed system in all ironrequiring organisms to ensure that sufficient, but not deleterious, levels of iron are maintained. In humans, circulating iron levels are highly restricted owing to sequestration by host proteins which provide an effective 'nutritional immunity' barrier against invading microorganisms, which also require iron. In addition, microbial 
challenge actually induces mechanisms of further iron restriction [2]. Invading microorganisms, therefore, encounter an iron-limiting environment and must engage in a struggle with the host for this essential resource to survive.

The opportunistic fungal pathogen, Aspergillus fumigatus has evolved a plethora of adaptations for the acquisition of iron [3]. It is the most prevalent airborne fungal pathogen and a leading cause of the potentially life-threatening disease, invasive aspergillosis (IA) in immunedeficient hosts [4]. During iron starvation A. fumigatus utilises two high affinity iron uptake systems; reductive iron assimilation (RIA) and siderophore-assisted iron uptake. Though both systems are upregulated in vivo during infection, only siderophore-mediated iron acquisition has been implicated in virulence, whereby deletion of sidA, encoding an ornithine monooxygenase required for siderophore biosynthesis, severely attenuates organismal virulence $[5,6]$. Siderophores are low molecular mass ferric $\left(\mathrm{Fe}^{3+}\right)$ iron chelators, secreted by the majority of bacteria and fungi, and those secreted by A. fumigatus can bind iron with such high affinity (binding constants of $10^{20}-10^{50}$ ) that they can even chelate iron from host proteins [7].

A. fumigatus produces four hydroxamate type siderophores, including two intracellular siderophores, ferricrocin (FC) for iron storage and distribution in hyphae and its biosynthetic derivative hydroxyferricrocin (HFC) for iron storage in conidia [8]. An additional two extracellular siderophores are utilised for the uptake of iron; fusarinine $C$ (FSC) and its acetylated derivative triacetylfusarinine C (TAFC) [8]. Siderophore-mediated iron uptake commences with the secretion of desferri-FSC/TAFC $\left(\right.$ FSC $^{-\mathrm{Fe}} / \mathrm{TAFC}^{-\mathrm{Fe}}$ ) through an unknown mechanism. $\mathrm{FSC}^{-\mathrm{Fe}} / \mathrm{TAFC}^{-\mathrm{Fe}}$ chelate extracellular ferric iron and the siderophore: iron complex is taken back up by specific transporters of the siderophore iron transporter (SIT) protein subfamily [9,10]. FSC ${ }^{+\mathrm{Fe}}$ and $\mathrm{TAFC}^{+\mathrm{Fe}}$ are then hydrolysed by esterases SidJ or EstB, respectively, and released iron is either directly used by metabolic machinery or stored as ferri-FC $\left(\mathrm{FC}^{+\mathrm{Fe}}\right)$, while siderophore degradation products are then recycled [11-13]. A Saccharomyces cerevisiae mutant without siderophore transport and RIA systems was used to elucidate the substrate affinity of several siderophore transporters from other species, such as the $\mathrm{TAFC}^{+\mathrm{Fe}}$ receptor MirB [9]. Including MirB, A. fumigatus encodes 7 putative SITs, many of which still await characterisation [14]. Interestingly, SITs are conserved across fungi, even in species incapable of producing siderophores such as $S$. cerevisiae, which expresses the siderophore receptor Taf1p capable of binding TAFC ${ }^{+\mathrm{Fe}}$ [15-17]. Furthermore, siderophore transporters represent one of the few protein families restricted to fungi. Coupled to the importance of effective iron acquisition in vivo, interference with siderophore uptake, therefore, represents a promising drug target, but one which requires further study [18].

A number of studies have explored the A. fumigatus proteome; however despite the relevance of iron status to the host environment, little is known about the proteomic response of $A$. fumigatus to iron limitation [19-28]. Furthermore, transcriptional analysis has revealed that iron limitation induces significant alterations in 13\% of genes encoding proteins $[29,30]$. To date, proteomic profiling of membrane-associated proteins has proven somewhat intractable owing to the limitations of traditional proteomic profiling methods such as 2-D separation coupled with MS identification [31]. Plasma membrane-associated proteins of A. fumigatus grown in complete medium have been successfully identified using SDS-PAGE separation of total membrane preparations followed by 2D LC-MS/MS [32]. Advanced shotgun proteomic strategies have the potential to unveil entire groups of previously undetectable proteins including membrane proteins. Under iron limitation, membrane protein analysis therefore represents a means of revealing the path of siderophore-mediated iron acquisition as well as potential therapeutic candidates in A. fumigatus. Thus, herein we characterise the microsomal proteome of A. fumigatus under iron limitation to gain an insight into the type, and extent, of proteomic remodelling which occurs upon confrontation of an iron-limited environment.

\section{Methods}

\subsection{Fungal strains}

Fungal strains used were A. fumigatus wild-type ATCC46645 (obtained from the American Type Culture Collection, Manassas, VA, USA) and A. fumigatus $\triangle$ sidG (a kind gift from Professor Hubertus Haas, Innsbruck) [8].

\subsection{A. fumigatus growth in iron-deplete conditions}

Glassware used for culturing in iron-deplete conditions was treated with $1 \mathrm{mM}$ EDTA followed by $\mathrm{HCl}$ to remove trace iron. Deionised water was used in the preparation of all solutions to limit the introduction of iron. A. fumigatus was grown in minimal media, containing $1 \%(w / v)$ glucose, $7 \mathrm{mM} \mathrm{KCl}, 2 \mathrm{mM} \mathrm{MgSO} \cdot \cdot 7 \mathrm{H}_{2} \mathrm{O}, 11 \mathrm{mM} \mathrm{KH}_{2} \mathrm{PO}_{4}$, and trace elements as previously described [33]. Following autoclaving, filter sterilised L-glutamine was added to $20 \mathrm{mM}$ final concentration. For iron-replete cultures, $\mathrm{FeSO}_{4}$ was included at $10 \mu \mathrm{M}$, final concentration. Cultures were inoculated with A. fumigatus ATCC46645 at $10^{6}$ conidia/ $\mathrm{ml}$, and grown at $200 \mathrm{rpm}, 37^{\circ} \mathrm{C}$ for up to $72 \mathrm{~h}$.

\subsection{Siderophore detection}

Following preliminary analysis for siderophore production using the SideroTec assay (www.emergenbio.com, Ireland), culture supernatants from iron-deplete and iron-replete cultures of A. fumigatus were analysed by RP-HPLC for the detection of extracellular siderophores at $254 \mathrm{~nm}$. Supernatants were brought to $1.5 \mathrm{mM} \mathrm{FeSO}_{4}$ and ferrated siderophores were detected by absorbance at $440 \mathrm{~nm}\left(\lambda_{\max }\right.$ of ferrated siderophores). Peaks associated with $\mathrm{FSC}^{+\mathrm{Fe}}$ and $\mathrm{TAFC}^{+\mathrm{Fe}}$ were fraction collected and identity confirmed via LC-MS.

\subsection{Siderophore purification}

For $\mathrm{FSC}^{+\mathrm{Fe}}$ purification, iron-deplete media was inoculated with $A$. fumigatus $\Delta$ sidG at $10^{6}$ conidia/ml, and grown at $200 \mathrm{rpm}, 37^{\circ} \mathrm{C}$ for $48 \mathrm{~h}$. Supernatants were harvested and frozen at $-20^{\circ} \mathrm{C}$ until use. Thawed supernatants were centrifuged at $4150 \mathrm{~g}, 4{ }^{\circ} \mathrm{C}$ for $30 \mathrm{~min}$, followed by filtration ( $0.45 \mu \mathrm{m}$ cellulose acetate; Sartorius). Clarified supernatants were applied to $C_{18}$ cartridges ( $500 \mathrm{mg}$ Sep-Pak Vac $3 \mathrm{~cm}^{3}$; Waters) (50 ml/application), equilibrated with $0.1 \%(v / v)$ TFA in deionised water. Columns were washed with $0.1 \%(v / v)$ TFA in deionised water and metabolites eluted in $100 \%$ methanol. Methanol eluates were reduced in volume 10 -fold by evaporation (SpeedVac Concentrator; Thermo Scientific). Concentrated metabolite extracts were ferrated in excess with $\mathrm{FeSO}_{4}$ before RP-HPLC purification of $\mathrm{FSC}^{+\mathrm{Fe}}$. $\mathrm{RP}-\mathrm{HPLC}$ purified $\mathrm{FSC}^{+\mathrm{Fe}}$ fractions were pooled and the eluting acetonitrile evaporated before $\mathrm{pH}$ adjustment to 7 with $1 \mathrm{M}$ sodium phosphate $\mathrm{pH}$ 7.0.

\subsection{RP-HPLC analysis}

RP-HPLC analysis was carried out using an Agilent Series 1200 HPLC System with a diode array (DAD) and fluorescence (FLD) detector and separation across a water: acetonitrile gradient with $0.1 \%(v / v)$ TFA. For analysis and quantification of siderophores in supernatants, gradient conditions of $5-100 \%$ acetonitrile over $35 \mathrm{~min}$ at $1 \mathrm{ml} / \mathrm{min}$ were used on a $\mathrm{C}_{8}$ column (Agilent Zorbax Eclipse XDB-C8 Analytical; $5 \mu \mathrm{m}$ particle size; $4.6 \times 150 \mathrm{~mm}$ ) with DAD detection at 254 and $440 \mathrm{~nm}$. Peaks associated with extracellular siderophores were collected by fractionation and identity confirmed via LC-MS. Purification of $\mathrm{FSC}^{+\mathrm{Fe}}$ was carried out with gradient conditions of 5-55\% acetonitrile over $22 \mathrm{~min}$ at $2 \mathrm{ml} / \mathrm{min}$ on a $\mathrm{C}_{18}$ column (Agilent Zorbax Eclipse XDB-C18 SemiPreparative; $5 \mu \mathrm{m}$ particle size; $9.4 \times 250 \mathrm{~mm}$ ) with DAD detection at 
254 and $440 \mathrm{~nm}$. The peak associated with $\mathrm{FSC}^{+\mathrm{Fe}}$ was collected by repeated fractionation and fractions pooled.

\subsection{Microsome preparation}

For microsome preparation, iron-deplete and iron-replete media were inoculated with A. fumigatus ATCC46645 at $10^{6}$ conidia/ml, and grown at $200 \mathrm{rpm}, 37^{\circ} \mathrm{C}$ for $72 \mathrm{~h}$. Mycelia were harvested through Miracloth, dried between tissue and snap-frozen in liquid nitrogen. Mycelia were lyophilised and protein was extracted using bead beating and ultra-sonication. Lysis buffer (0.2 M Tris-HCl, $20 \mathrm{mM}$ EDTA, $1 \mathrm{mM}$ PMSF, pH 8.0) was used in the extraction as previously described [32]. Extracts were centrifuged at $10,000 \mathrm{~g}, 20 \mathrm{~min}, 4^{\circ} \mathrm{C}$ to remove cell debris and the cell wall. Clarified lysates (referred to as whole cell extracts) were subjected to ultracentrifugation at $150,000 \mathrm{~g}, 4^{\circ} \mathrm{C}$ for $1 \mathrm{~h}$. The supernatant was removed from the tube and retained as the 'soluble' protein fraction. The pellet was resuspended in ice-cold lysis buffer using a $27 \mathrm{G}$ needle to aid resuspension. Ultracentrifugation was repeated twice more. For SDS-PAGE analysis (7.5\% or 12\%) pellets were resuspended in $5 \times$ solubilisation buffer. Alternatively, for in-solution digestion, pellets were resuspended in $8 \mathrm{M}$ Urea using a 27G needle and quantified using the Bradford assay. Aliquots of the whole cell and soluble protein preparations were precipitated with TCA followed by acetone washes and resuspended in $8 \mathrm{M}$ Urea.

\subsection{In-gel digestion for analysis of SDS-PAGE separated samples}

The processing of SDS-PAGE bands was carried out as previously described [34]. Gel pieces were destained and trypsin (Promega) digested overnight, peptide mixtures were dried to completion and resuspended in $0.1 \%(v / v)$ formic acid for LC-MS analysis. Analysis of digested peptides was carried out using an Agilent 6340 Ion Trap LC-MS as described below.

\subsection{In-solution digestion for label-free proteomics}

Microsome, whole cell and soluble fractions were reduced and alkylated, followed by trypsin digestion in the presence of the MScompatible detergent ProteaseMax (Promega). Briefly, microsome fractions were combined with ProteaseMax to aid solubilisation. Samples were diluted to lower the urea concentration, followed by reduction using DTT (final $5 \mathrm{mM}$ ) for $20 \mathrm{~min}$ at $56{ }^{\circ} \mathrm{C}$. Samples were allowed to cool and alkylated using IAA at $15 \mathrm{mM}$, in the dark for $15 \mathrm{~min}$. Samples were then trypsin digested overnight in the presence of ProteaseMax and digestion was stopped by addition of formic acid to $1 \%(v / v)$ prior to analysis by LC-MS [35-37].

\subsection{Mass spectrometry using LC-MS/MS}

Preliminary LC-MS analysis was carried out on a nanoflow Agilent 1200 LC system and subjected to tandem mass spectrometry using an Agilent 6340 Ion Trap LC-MS System (Agilent Technologies, Santa Clara, CA). Peptides or RP-HPLC purified siderophores were applied to a Zorbax SB-C18 HPLC-Chip with a $40 \mathrm{nl}$ enrichment column and a $75 \mu \mathrm{m} \times 43 \mathrm{~mm}(5 \mu \mathrm{m}$ particle and 300 Å pore size) analytical column $[28,38]$. For high sensitivity, label-free comparative proteomics, nano LC-MS/MS analysis was carried out using an Ultimate 3000 RSLC nanoLC system (Dionex) coupled to a hybrid linear ion trap/Orbitrap mass spectrometry (LTQ Orbitrap XL; Thermo Fisher Scientific) as previously described [39]. Briefly, $1 \mu \mathrm{g}$ of microsome digests from each of four biological replicates, grown in either iron-deplete or iron-replete conditions, were separated on an Acclaim PepMap C18 column, $75 \mu \mathrm{m}$ ID $\times$ $50 \mathrm{~cm}, 3 \mu \mathrm{m}$ particle and $100 \AA \AA$ pore size (Dionex), across a $5 \mathrm{~h}$ acetonitrile gradient. Data were acquired with Xcalibur software and the mass spectrometer was operated in data-dependent mode. Survey MS scans were acquired in the Orbitrap at a resolution of 30,000 at $\mathrm{m} / \mathrm{z} 400$. A
Top 3 method (3 MS/MS collected per MS scan) was used for the label-free quantitative comparisons while a separate run was performed using a Top 20 method for qualitative analysis.

\subsection{Data analysis for proteomic profiling}

For preliminary LC-MS analysis of whole cell, microsome and soluble fractions database searches were carried out using Spectrum Mill MS Proteomics Workbench (Revision B.04.00.127). Validation criteria were set to (i) maximum of two missed cleavages by trypsin, (ii) fixed modification: carbamidomethylation of cysteines, (iii) variable modifications: oxidation of methionine, (iv) mass tolerance of precursor ions $\pm 2.5 \mathrm{Da}$ and product ions $\pm 0.7 \mathrm{Da}$ were employed and searches were carried out against a protein database of $A$. fumigatus strains Af293 (reference strain) and A1163, acquired from AspGD (www.aspgd.org). Label-free LC-MS comparative analysis was carried out using MaxQuant (version 1.3.0.5), as previously described [37], with LFQ algorithm engaged for protein ratio determination. Database searching was performed using Andromeda, against a protein database consisting of A. fumigatus Af293 and A1163 strains. Protein and peptide FDRs were set to $1 \%$, with a reverse database search used. Perseus (version 1.4.1.3) was used to organise the data and generate scatter plots, with a minimum of 2 peptides per protein accepted for identification. Results were further filtered to include only proteins identified from a minimum of 3 replicates from either sample set. Qualitative results were generated based on a protein being uniquely detected in either condition. This was dependant on the detection of a protein in at least $3 / 4$ biological samples from one condition, and absence of detection in all replicates of the second condition. Additional quantitative comparison of membrane protein samples was conducted using Progenesis labelfree LC-MS software version 3.1 (NonLinear Dynamics), as described by the manufacturer (www.nonlinear.com). Samples were aligned based on $\mathrm{LC}$ retention times and $\mathrm{m} / \mathrm{z}$ ratios, to adjust for any retention time drift across all of the runs. Peak intensities were normalised to a reference run and relative peptide abundances were calculated based on the summed area of its isotope cluster. Protein abundances were then determined by combining peptide values. Peptide features that displayed a significant difference between the iron-deplete and ironreplete conditions (ANOVA $<0.05$ ), were exported for identification using MASCOT version 2.2 (www.matrixscience.com). Database searching was performed against a protein database consisting of $A$. fumigatus Af293 and A1163 strains. The search parameters included: peptide mass tolerance set to $20 \mathrm{ppm}$, MS/MS tolerance set at $0.6 \mathrm{Da}$, up to 2 missed cleavages allowed, carbamidomethylation of cysteine as a fixed modification and oxidation of methionine as a variable modification. Only peptides with ion scores $\geq 40$ were imported back into Progenesis LC-MS for further analysis. Proteins with $\geq 2$ peptides used for quantitation and with $\mathrm{a} \geq 2$ fold change in abundance were reported in the quantitative results. Using Phobius (http://phobius.cbr.su.se), the number of putative transmembrane regions present in each identified protein was determined. Functional category enrichment was analysed using the FungiFun application (https://www.omnifung.hki-jena.de/ FungiFun/) [40].

\subsection{Fluorescent labelling of $\mathrm{FSC}^{+\mathrm{Fe}}$}

$\mathrm{FSC}^{+\mathrm{Fe}}(70 \mu \mathrm{mol})$, purified from culture supernatants of $A$. fumigatus $\triangle$ sidG as described above, was resuspended in sodium phosphate $\mathrm{pH}$ 7.0. Fluorescent labelling was achieved via sequential addition of amino-reactive succinimidyl 6-( $\mathrm{N}$-(7-nitrobenz-2-oxa,1,3-diazol-4yl)amino)hexanoate (NBD-SE) (21 $\mu \mathrm{mol}$ total) (Life Technologies) in DMSO. Controls including FSC ${ }^{+\mathrm{Fe}}$ only, NBD-SE only, and reaction diluent only were treated accordingly in parallel. After addition of NBD-SE each reaction was allowed to proceed for $0.5-1 \mathrm{~h}$ at room temperature in the dark and followed by RP-HPLC analysis to confirm fluorescent labelling. For analysis of fluorescently labelled $\mathrm{FSC}^{+\mathrm{Fe}}$, FLD detection at 
Ex/Em 466/535 nm was employed (Ex/Em of NBD). Peaks novel to NBD$\mathrm{FSC}^{+\mathrm{Fe}}$ (not in NBD-SE or FSC ${ }^{+\mathrm{Fe}}$ alone) simultaneously absorbing at

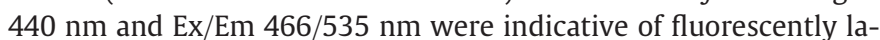
belled $\mathrm{FSC}^{+\mathrm{Fe}}$. Fluorescent labelling was also confirmed by LC-MS. Any amino-reactivity of free NBD-SE was quenched via the addition of $1 \mathrm{M}$ Tris- $\mathrm{HCl}(426 \mu \mathrm{mol}) \mathrm{pH} 7$ followed by storage at $-20^{\circ} \mathrm{C}$ until use.

\subsection{Fluorescent siderophore uptake}

A. fumigatus ATCC46645 conidia ( $4 \times 10^{5}$ per well in a 6 well plate) were added to iron-deplete and replete minimal media ( $4 \mathrm{ml} /$ well) with each well containing a glass coverslip. Plates were incubated statically at $37^{\circ} \mathrm{C}$ for $21 \mathrm{~h}$, after which the top layer of mycelia was removed and adherent mycelia washed 3 times with corresponding fresh media. Filter sterilised NBD-FSC ${ }^{+\mathrm{Fe}}$, as well as controls including FSC ${ }^{+\mathrm{Fe}}$, NBD$\mathrm{SE}$, and reaction diluent were added to media to a concentration equivalent to $0.1 \mathrm{mM} \mathrm{FSC}^{+\mathrm{Fe}}$. Plates were further incubated statically at $37^{\circ} \mathrm{C}$ for $1 \mathrm{~h}$, followed by removal of supernatant and 4 PBS washes. After removal of PBS, mycelia were visualised using a fluorescent microscope (Olympus BX51; GFP filter: Ex/Em 492-495 nm/517-527 nm).

\subsection{Indirect ELISA}

96-well Maxisorp Nunc immunoassay plates (Thermo Fisher Scientific) were coated with $100 \mu \mathrm{l}$ of iron-deplete and replete microsomal protein fractions at $5 \mu \mathrm{g} / \mathrm{ml}$ in $50 \mathrm{mM}$ sodium carbonate $\mathrm{pH} 9.6$ at $4{ }^{\circ} \mathrm{C}$ overnight. Plates were washed three times with PBST (pH 7.3, 0.05\% Tween-20) then blocked with blocking buffer in PBST at $37^{\circ} \mathrm{C}$ for $1 \mathrm{~h}$. Blocking solution was poured off and plates were allowed to dry at $37^{\circ} \mathrm{C}$ for $1 \mathrm{~h}$. Human serum (obtained, with permission, from the Irish Blood Transfusion Service) diluted 1 in 100 in 1\% BSA in PBST and $100 \mu \mathrm{l}$ was added to each well. Plates were incubated at $37^{\circ} \mathrm{C}$ for $1 \mathrm{~h}$. Plates were washed 3 times with PBST. $100 \mu$ of goat anti-human IgGHRP diluted 1 in 10,000 in 1\% BSA in PBST was added to each well. Plates were incubated at $37^{\circ} \mathrm{C}$ for $1 \mathrm{~h}$. Plates were washed 3 times with PBST. $100 \mu$ of tetramethylbenzidine (TMB; Moss Inc) was added to each well. Plates were incubated at room temperature for $10 \mathrm{~min} .100 \mu \mathrm{l}$ of $1 \mathrm{~N}$ sulfuric was added to each well. Absorbances were determined at 450/ 630 nm (Synergy ${ }^{\mathrm{TM}}$ HT; BioTek Instruments).

\section{Results}

\subsection{Iron depletion induces siderophore production and facilitates FSC purification and characterisation}

Comparative analysis of culture supernatants with detection at $254 \mathrm{~nm}$ revealed significantly elevated levels of $\mathrm{FSC}^{-\mathrm{Fe}}$ and $\mathrm{TAFC}^{-\mathrm{Fe}}$ in iron-deplete compared to iron-replete cultures $(p<0.0001)$ (Figs. S1 and S2). Addition of $\mathrm{FeSO}_{4}$ to aliquots of culture supernatants facilitated detection at the $\lambda_{\max }$ of siderophores ( $440 \mathrm{~nm}$ ) and increased the sensitivity of detection. Ferrated supernatant analysis also demonstrated a significant elevation in FSC and TAFC levels under ironlimiting conditions $(p<0.0001)$ (Fig. S2). Supernatants from A. fumigatus $\Delta$ sidG grown in iron limitation were $\mathrm{C}_{18}$ concentrated into methanol and ferrated in excess with $\mathrm{FeSO}_{4}$ followed by RP-HPLC purification of $\mathrm{FSC}^{+\mathrm{Fe}}$ (Fig. S3). Purity of resultant $\mathrm{FSC}^{+\mathrm{Fe}}$ was then confirmed by co-detection at $254 \mathrm{~nm}$ and $440 \mathrm{~nm}$ (Fig. S3). FSC and TAFC identity was confirmed by LC-MS (Fig. 1).

\subsection{Ultracentrifugation effects microsomal enrichment following growth under iron-stress}

To investigate if proteins involved in iron mobilisation and transport were differentially abundant in the membrane extracts from mycelia grown in iron-deplete relative to iron-replete conditions, SDS-PAGE analysis of microsomal fractions was undertaken. This indicated that several bands visible on both the $12 \%$ and the $7.5 \%$ polyacrylamide gels were unique to each condition (Fig. S4) and LC-MS analysis revealed 22 membrane-associated proteins; 5 proteins unique to irondeplete conditions and 6 unique to iron-replete, in addition to 11 shared between the conditions (Table 1). Protein presence in total and microsomal extracts was also subjected to qualitative analysis using an Agilent Ion Trap coupled to nanoLC. In the whole cell preparation, $7.11 \%$ and $4.33 \%$ of the proteins identified in iron-deplete and replete extracts respectively, were predicted to contain transmembrane (TM) regions (Supplementary Table 1 ). However, derived microsomal preparations were found to consist of $28.57 \%$ and $24.67 \%$ of proteins with predicted TM regions, in the iron-replete and deplete conditions, respectively (Supplementary Table 1). This confirms a 4-6 fold enrichment of proteins with predicted TM regions following ultracentrifugation-based microsomal preparation. Furthermore, microsomal preparation led to the identification of a large number of proteins that were previously undetectable in the whole cell preparation (Fig. S4). Approximately 60\% of the proteins detected in the microsomal fractions were undetectable in analyses carried out on the samples prefractionation (Whole cell), representing a substantial increase in proteome coverage, achieved through cellular fractionation (Fig. S4) (Supplementary Table S2).

\subsection{Label-free quantitative proteomic analysis reveals altered abundance of iron-responsive proteins}

Tryptic digests of A. fumigatus microsomal fractions, from ironreplete and iron-deplete growth conditions, were separated using $5 \mathrm{~h}$ gradients and analysed using an Orbitrap LTQ XL as described. Data from biological replicates $(n=4)$ from each growth condition were used in the label-free study and both MaxQuant and Progenesis LC-MS were utilised for independent generation of quantitative results. Scatterplot analysis carried out in MaxQuant demonstrated high correlation amongst biological replicates from each growth condition (Pearson correlation $>0.96$ within groups), thus validating the reproducibility of the microsomal preparation, digestion and LC-MS analysis (Fig. 2). Furthermore, correlation between the microsomal samples from iron-deplete or replete conditions also remained high (Pearson correlation $>0.84$ ) (Fig. 2), which confirms that sample groups were suitable for comparative analysis. Using the search and validation criteria outlined, 710 unique proteins were identified in total. Quantitative comparison revealed 84 proteins ( $12 \%$ of total detected) with a significant change in abundance between the iron-replete and irondeplete conditions ( $p<0.05$, fold change $\geq 2$ ), with 35 proteins showing increased abundance and 49 with decreased abundance following iron limitation. Progenesis LC-MS was also utilised for parallel assessment of quantitative results. Using a minimum of two peptides for quantitation, significant changes in abundance were evident for 209 unique proteins in response to iron depletion $(p<0.05)$. Further data filtering identified proteins which underwent at least a two-fold change in abundance (134 proteins), with 65 proteins showing a significant increase and 69 showing decreased abundance in response to iron starvation $(p<0.05$; fold change $\geq 2$ ) (Table S3). A number of proteins, with siderophore-related functions, were observed to increase significantly in abundance in the iron-deplete microsomal fractions, including putative transporters MirB and Sit1, and non-ribosomal peptide synthetases (NRPS) involved in both intracellular (SidC) and extracellular (SidD) siderophore biosynthesis (Table 2).

3.4. Label-free quantitative ( $L F Q$ ) comparative proteomic analysis reveals de novo presence of iron-responsive proteins

Qualitative differences in microsomal protein presence, in response to iron-limited conditions, were defined based on protein detection in at least 3 of the 4 biological replicates of a given condition and absence of detection in the alternate condition. These were determined using 
A

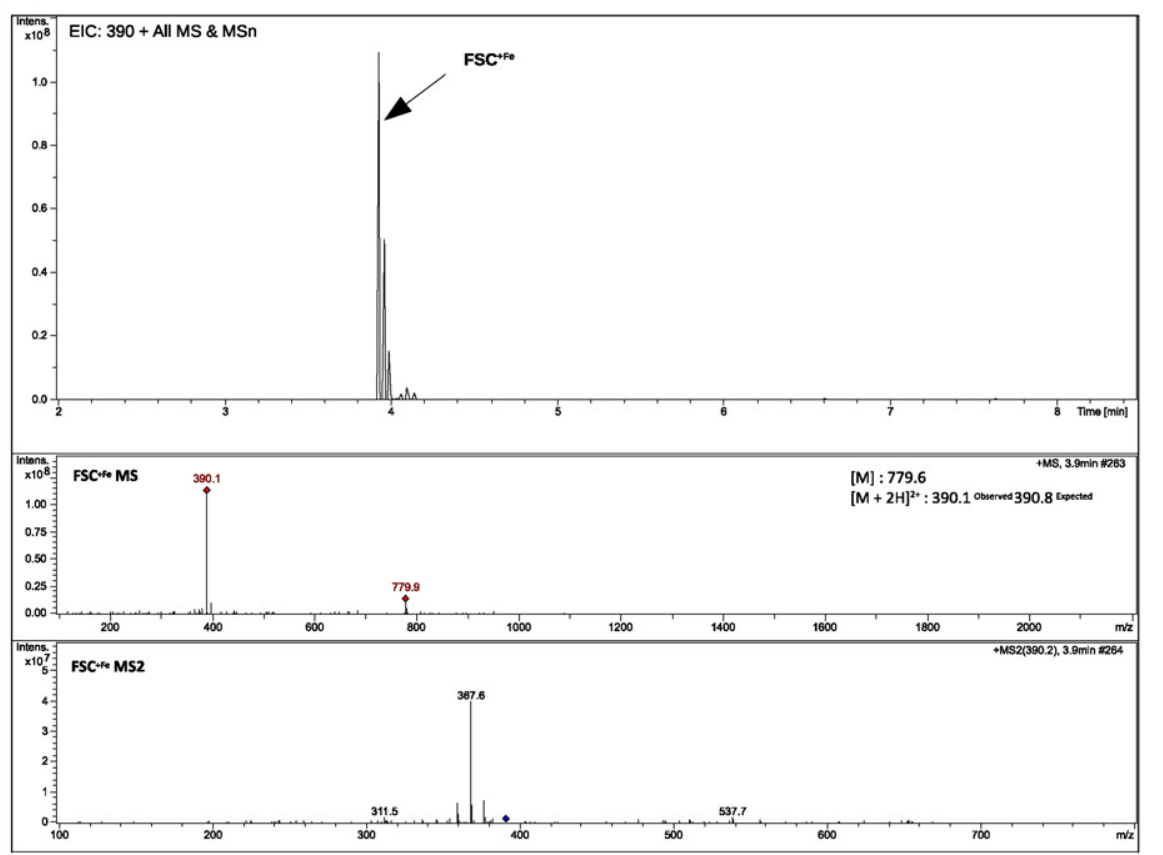

B

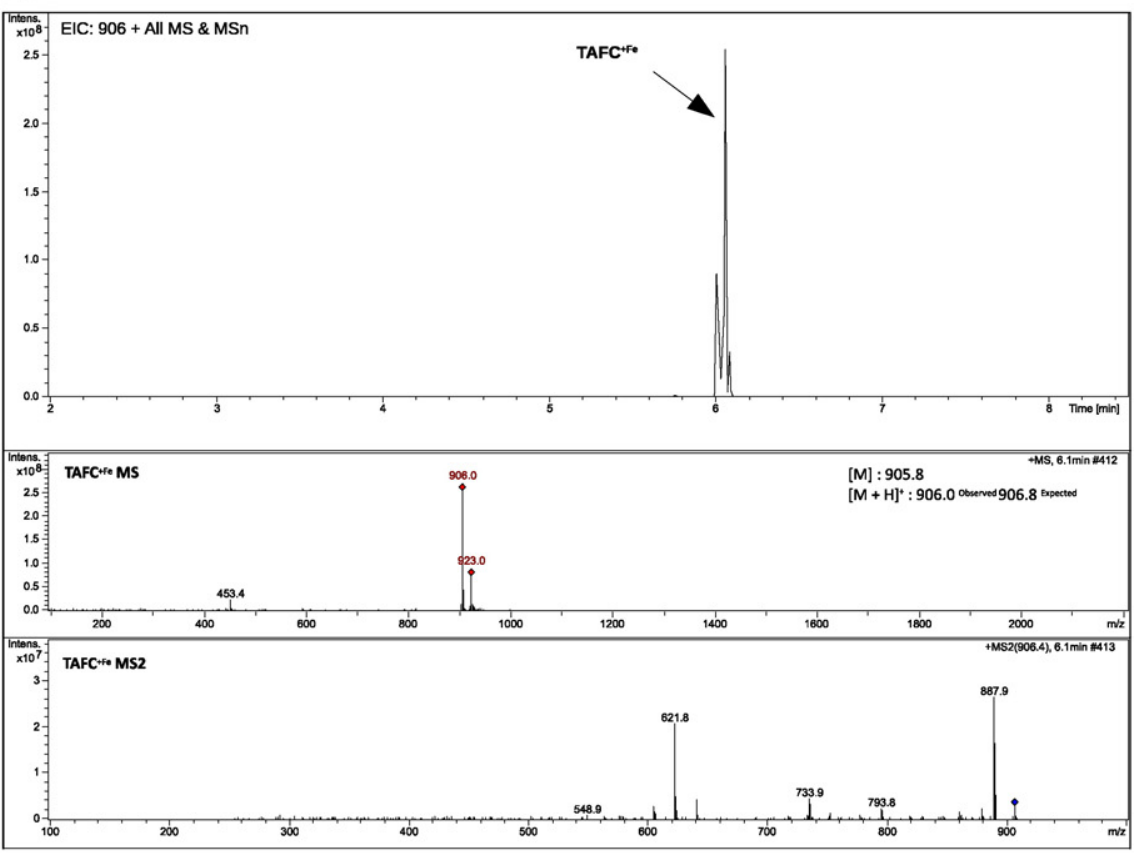

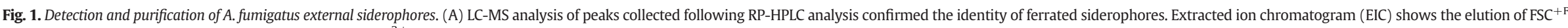

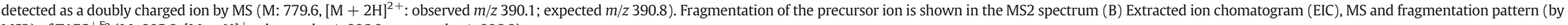
MS2) of TAFC ${ }^{+\mathrm{Fe}}$ (M: 905.8, [M $\left.+\mathrm{H}\right]^{+}$: observed $m / z$ 906.0; expected $m / z$ 906.8). 
Table 1

Microsomal-associated proteins identified in A. fumigatus by LC-MS following SDS-PAGE fractionation.

\begin{tabular}{|c|c|c|}
\hline CADRE ID & Protein name & $\begin{array}{l}\text { \% Seq. coverage } \\
\text { (peptides detected) }\end{array}$ \\
\hline \multicolumn{3}{|c|}{ Both iron-replete/deplete conditions } \\
\hline AFUA_4G14380 & Glutathione S-transferase & 31 (8 peptides) \\
\hline AFUA_1G06390 & Translation elongation factor EF-1subunit & 17 (6 peptides) \\
\hline AFUA_8G02550 & MFS oligopeptide transporter, POTfamily & 10 (4 peptides) \\
\hline AFUA_6G06900 & RhoGTPase Rho1 & 16 (6 peptides) \\
\hline AFUA_2G14990 & Tubulin alpha-2subunit & 4 (2 peptides) \\
\hline AFUA_2G10030 & Actin cytoskeleton protein VIP1 & 21 (4 peptides) \\
\hline AFUA_4G10350 & PolyubiquitinUbiD/Ubi4 & 9 (2 peptides) \\
\hline AFUA_4G12850 & Calnexin & 4 (2 peptides) \\
\hline AFUA_2G12400 & $\begin{array}{l}\text { ATP synthase oligomycin sensitivity } \\
\text { conferral }\end{array}$ & 9 (2 peptides) \\
\hline AFUA_5G02470 & Thiamine biosynthesis protein Nmt1 & 18 (4 peptides) \\
\hline AFUA_6G13250 & $60 S$ ribosomal protein $\mathrm{L} 31 \mathrm{e}$ & 16 (2 peptides) \\
\hline \multicolumn{3}{|c|}{ Iron-replete conditions } \\
\hline AFUA_6G03060 & Monosaccharide transporter Mch4 & 9 (5 peptides) \\
\hline AFUA_3G14170 & High affinity hexose transporter & 9 (4 peptides) \\
\hline AFUA_3G03700 & Sugar transporter subfamily & 4 (2 peptides) \\
\hline AFUA_7G01010 & Alcohol dehydrogenase & 19 (4peptides) \\
\hline AFUA_3G11390 & $\begin{array}{l}\text { Proteasome regulatory particle subunit } \\
\text { Rpt3 }\end{array}$ & 6 ( 2 peptides) \\
\hline AFUA_1G10630 & S-adenosylmethionine synthetase & 6 (2 peptides) \\
\hline \multicolumn{3}{|c|}{ Iron-deplete conditions } \\
\hline AFUA_3G12900 & Monocarboxylate transporter Mch4 & 5 ( 3 peptides) \\
\hline AFUA_3G03640 & MFS siderochrome irontransporter MirB & 8 (3 peptides) \\
\hline AFUA_7G06060 & Siderochrome-iron transporter Sit1 & 3 (2 peptides) \\
\hline AFUA_3G03430 & $\mathrm{ABC}$ multidrug transporter SitT & 2 (2 peptides) \\
\hline AFUA_4G08580 & Mitochondrial peroxiredoxin Prx1 & 9 (2 peptides) \\
\hline
\end{tabular}

MaxQuant and yielded 86 and 61 proteins that were uniquely identified in iron-replete and iron-deplete conditions, respectively (Table S3). Relevant microsomal-associated proteins that were uniquely detected in the iron-deplete condition included the putative siderophore transporters SitT and MirD, in addition to siderophore biosynthesis-related proteins SidA (L-ornithine N5-oxygenase), SidG (FSC acetyltransferase) and SidD (FSC NRPS) (Table 2). SidD and MirD were also the most abundant proteins that were uniquely detected in iron-depleted microsomal samples, along with the ABC transporter encoded by AFUA_3G03670, which is found in an iron-regulated cluster on Chromosome 3 (Table 3).

Proteins identified by MaxQuant with qualitative or quantitative changes in response to iron depletion were analysed using FungiFun [40]. Gene Ontology (GO) term enrichment $(p<0.05)$ was observed for proteins altered in abundance in the iron-deplete microsomes compared to iron-replete (Fig. 2). A background list of all identified proteins was included, to eliminate any influence of cellular fractionation on the GO term enrichment analysis. Proteins involved in biological processes such as nucleosome assembly, protein targeting and protein modification process were increased in abundance under iron-limited conditions. Proteins with a decreased abundance following iron starvation were highly enriched for oxidation-reduction processes (Fig. 2). This is reflected in the appearance of multiple proteins with oxidationreduction functions amongst proteins with the highest abundance that were uniquely detected in iron-replete samples, including Catalase $\mathrm{C}$, cytochrome $\mathrm{C}$ peroxidase (CCP) and NADH-ubiquinone oxidoreductases (AFUA_4G11150 and AFUA_6G04620) (Table 3).

\subsection{Fluorescently labelled $\mathrm{FSC}^{+F e}$ is taken up by A. fumigatus under iron-} deplete conditions

Purified $\mathrm{FSC}^{+\mathrm{Fe}}$ was derivatized with NBD-SE and products analysed by RP-HPLC with detection at $440 \mathrm{~nm}$ and Ex/Em 466/535 nm (Fig. 3). $\mathrm{FSC}^{+\mathrm{Fe}}$ and NBD-SE were treated in parallel as controls. The presence of peaks in NBD-FSC ${ }^{+\mathrm{Fe}}$, but absent from $\mathrm{FSC}^{+\mathrm{Fe}}$ or NBD-SE alone, simultaneously absorbing at $440 \mathrm{~nm}$ with $\mathrm{Ex} / \mathrm{Em}$ 466/535 nm confirmed the successful generation of NBD-FSC ${ }^{+\mathrm{Fe}}$ (Fig. 3). Multiple peaks with these properties were generated, likely resulting from modification of 1,2 , or all 3 of the available amino groups of $\mathrm{FSC}^{+\mathrm{Fe}}$. LC-MS confirmed synthesis of NBD-labelled $\mathrm{FSC}^{+\mathrm{Fe}}$ whereby presence of monoderivatized-FSC ${ }^{+\mathrm{Fe}}\left(\mathrm{M}: 1054.9,[\mathrm{M}+2 \mathrm{H}]^{2+}\right.$ : observed $\mathrm{m} / \mathrm{z}$ 528.5; expected $m / z$ 528.5) was apparent (Fig. 3). Using a novel assay, NBD-FSC ${ }^{+\mathrm{Fe}}$ uptake only by A. fumigatus grown under iron-deplete conditions was observed (Fig. 3). Moreover, fluorescent siderophore appears localised to vacuoles in A. fumigatus grown in iron-deplete but not iron-replete conditions (Fig. 3).

\subsection{Significantly elevated human IgG reactivity against microsomal protein extracts obtained from iron-deplete conditions}

Microsomal proteins from A. fumigatus grown in iron-deplete and replete conditions, respectively, were immobilised on microwell plates $(5 \mu \mathrm{g} / \mathrm{ml})$. Immune-competent human sera $(n=85)$ was analysed in a master pool $(n=1)$ and mini-pools, with each containing 5 serum specimens $(n=17)$. The 3 mini-pools with the highest immunoreactivity were selected and the constituent sera analysed $(n=15)$. Master pool $(n=1)$ analysis revealed significantly higher immunoreactivity towards iron-deplete proteins ( $p<0.0001$ ) (Fig. 4). Of the 17 mini-pools analysed, there was a significant difference between the immunoreactivity towards iron-replete and deplete proteins $(p<0.01) .8$ were more immunoreactive to iron-deplete proteins $(p<0.05)$ and 2 were more immunoreactive to iron-replete proteins $(p<0.05)$ (Fig. 4). Of the 15 individual sera analysed, 11 were more immunoreactive to iron-deplete microsomal protein extracts $(p<0.05)$, while only one exhibited greater immunoreactivity towards microsomal proteins extracted from iron-replete cultures $(p<0.05)$ (Fig. 4). This observation strongly indicates that microsomal proteins associated with irondeplete conditions are present during exposure of immunocompetent individuals to A. fumigatus.

\section{Discussion}

Siderophore-mediated iron acquisition strategies are essential for the virulence of $A$. fumigatus owing to the struggle for iron during infection. Despite the importance of this environmental cue to host colonisation and the magnitude of the transcriptional remodelling that occurs under such stress $[29,41]$, only limited knowledge exists on the ironstarved proteome of $A$. fumigatus. Specifically, membrane proteins represent a focal point of the host: pathogen interface and a crucial facet of the functional remodelling undertaken to ensure survival therein by facilitating systems for proficient nutrient supply. Utilising high sensitivity proteomics we have complemented current transcriptional knowledge on a protein level and further dissected alterations in the membrane systems of A. fumigatus under iron starvation. Using conditions under which siderophore biosynthesis and uptake are utilised, significant alterations to the microsomal proteome of $A$. fumigatus have been observed. The successful enrichment of microsomal extracts has expedited the identification of putative siderophore transporters not previously detected on a protein level or implicated in iron sensitivity. Fluorescent derivatisation of $\mathrm{FSC}^{+\mathrm{Fe}}$ permitted visualisation of siderophore uptake, which occurs during iron-deplete but not replete growth and reveals a vacuolar localisation during siderophore processing. Immune-competent human serum exhibited higher immunoreactivity to iron-deplete versus replete microsomal proteins validating the relevance of the investigated phenotype in host recognition.

Sufficiently iron-deplete and replete growth conditions were confirmed via RP-HPLC and LC-MS analysis of supernatants with siderophore production as an indicator (Figs. 1, S1 and S2). Microsomal extracts were prepared and initially analysed by SDS-PAGE/LC-MS/MS leading to the identification of 93 microsome-associated proteins many of which were not identified by previous microsomal protein analysis [32], including proteins involved in siderophore biosynthesis 
A

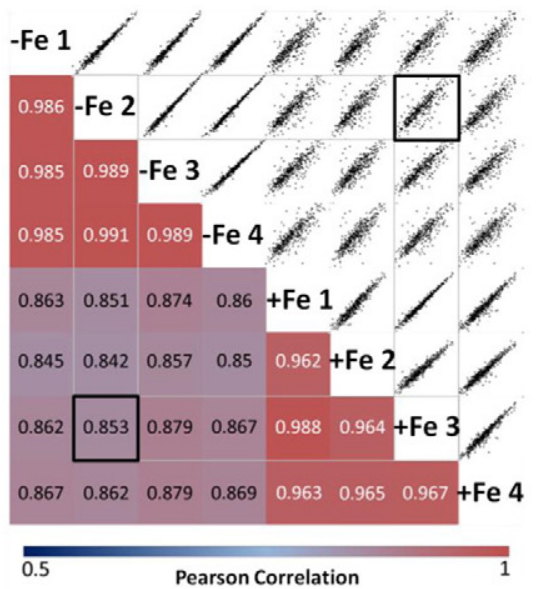

B

\section{GO terms enriched in proteins decreased in response to iron depletion}

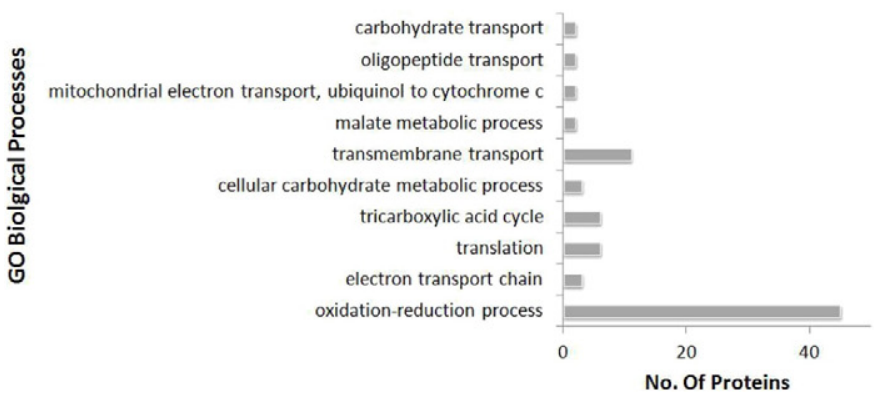

\section{GO terms enriched in proteins increased in response to iron depletion}

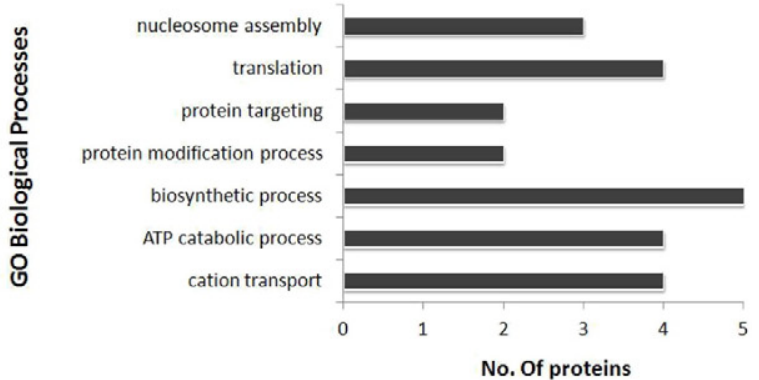

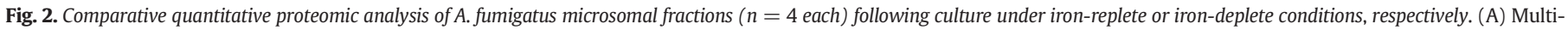

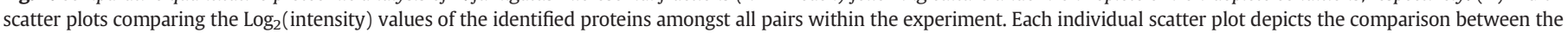

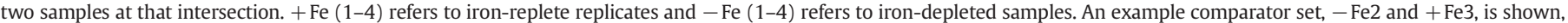

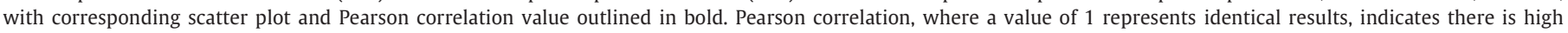

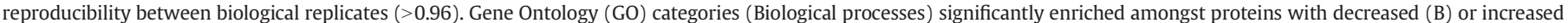
(C) abundance following growth in iron-deplete conditions $(p<0.05)$.

and metabolism (Fig. S4). Initial LC-MS analysis of microsomal protein extracts obtained following iron-deplete culture revealed a 6-fold enrichment in proteins containing transmembrane domains, and specifically the presence of membrane proteins Sit1, SitT and MirB which have been proposed and demonstrated to be involved in siderophore release or uptake (Tables S1 and S2) [17,29,42,43].

Table 2

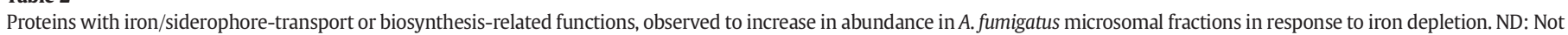
Detected, Unique to iron-depleted detected only in samples from iron-deplete cultures.

\begin{tabular}{|c|c|c|c|c|c|c|c|c|}
\hline \multirow[b]{2}{*}{$\begin{array}{l}\text { Accession } \\
\text { No. } \\
\text { AFUA_ }\end{array}$} & \multirow[b]{2}{*}{ Description } & \multirow[b]{2}{*}{$\begin{array}{l}\text { Protein } \\
\text { name }\end{array}$} & \multicolumn{3}{|c|}{ Progenesis LC-MS } & \multicolumn{3}{|l|}{ MaxQuant } \\
\hline & & & $\begin{array}{l}\text { Fold } \\
\text { Change }\end{array}$ & $\begin{array}{l}\mathrm{P} \\
\text { value }\end{array}$ & $\begin{array}{l}\text { Peptides } \\
\text { detected }\end{array}$ & Fold change & $\begin{array}{l}\mathrm{P} \\
\text { value }\end{array}$ & $\begin{array}{l}\text { Peptides } \\
\text { detected }\end{array}$ \\
\hline 2G07680 & L-ornithine N5-oxygenase SidA; first committed step in siderophore biosynthesis & SidA & 3.88 & 0.01 & 2 & $\begin{array}{l}\text { Unique to } \\
\text { iron-depleted }\end{array}$ & & 6 \\
\hline $1 \mathrm{G} 17200$ & $\begin{array}{l}\text { Putative non-ribosomal peptide synthetase (NRPS) involved in ferricrocin siderophore } \\
\text { biosynthesis }\end{array}$ & SidC & 13.75 & 0.0001 & 2 & ND & & \\
\hline $3 \mathrm{G} 03420$ & $\begin{array}{l}\text { Fusarinine C non-ribosomal peptide synthetase (NRPS) involved in extracellular } \\
\text { siderophore biosynthesis SidD }\end{array}$ & SidD & 11.8 & 3E-05 & 6 & $\begin{array}{l}\text { Unique to } \\
\text { iron-depleted }\end{array}$ & & 36 \\
\hline 3G03650 & $\begin{array}{l}\text { Putative acetyltransferase with a predicted role in iron metabolism SidG; located in an } \\
\text { iron-regulated gene cluster; fusarinine } C \text { acetyltransferase; SrbA-regulated during hypoxia }\end{array}$ & SidG & 79.95 & $4 \mathrm{E}-06$ & 2 & $\begin{array}{l}\text { Unique to } \\
\text { iron-depleted }\end{array}$ & & 3 \\
\hline $3 \mathrm{G} 03430$ & Putative $A B C$ multidrug transporter; biofilm growth regulated protein SitT & SitT & 66.95 & $1 \mathrm{E}-06$ & 4 & $\begin{array}{l}\text { Unique to } \\
\text { iron-depleted }\end{array}$ & & 12 \\
\hline 2G05730 & Putative siderophore transporter & MirA/C & 3.81 & $3 \mathrm{E}-06$ & 2 & ND & & \\
\hline $3 G 03640$ & Putative siderophore iron transporter MirB; SrbA-regulated during hypoxia & MirB & ND & & & 18.13 & 0.002 & 10 \\
\hline $3 G 03440$ & $\begin{array}{l}\text { Putative siderophore transporter MirD; expression upregulated under low iron conditions; } \\
\text { SrbA-regulated during hypoxia }\end{array}$ & MirD & 5.47 & 0.0005 & 2 & $\begin{array}{l}\text { Unique to } \\
\text { iron-depleted }\end{array}$ & & 8 \\
\hline $3 \mathrm{G} 03670$ & $\begin{array}{l}\text { ABC multidrug transporter with a predicted role in iron metabolism; part of an } \\
\text { iron-regulated gene cluster }\end{array}$ & & 5.83 & 0.0002 & 3 & $\begin{array}{l}\text { Unique to } \\
\text { iron-depleted }\end{array}$ & & 17 \\
\hline 7G06060 & Putative siderophore transporter (Sit1); SrbA-regulated during hypoxia & Sit1 & ND & & & 4.16 & 0.002 & 3 \\
\hline
\end{tabular}


Table 3

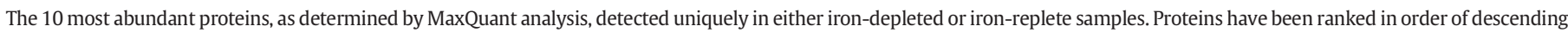
abundance.

\begin{tabular}{|c|c|c|c|c|c|c|c|}
\hline \multirow[b]{2}{*}{$\begin{array}{l}\text { Accession } \\
\text { (AFUA_) }\end{array}$} & \multirow[b]{2}{*}{ Description } & \multicolumn{3}{|c|}{ Progenesis LC-MS } & \multicolumn{3}{|l|}{ MaxQuant } \\
\hline & & $\begin{array}{l}\text { Fold } \\
\text { change }\end{array}$ & P value & $\begin{array}{l}\text { Peptides } \\
\text { detected }\end{array}$ & $\begin{array}{l}\text { Uniquely } \\
\text { detected in: }\end{array}$ & $\begin{array}{l}\text { Predicted } \\
\text { fold } \\
\text { change }^{1}\end{array}$ & $\begin{array}{l}\text { Peptides } \\
\text { detected }\end{array}$ \\
\hline \multicolumn{8}{|c|}{ Uniquely detected in iron-depleted samples } \\
\hline $3 G 03420$ & Nonribosomal peptide synthetase 4 EC 6.3.2.- (siderophore peptide synthase D, SidD) & 11.8 & $2.8 \mathrm{E}-05$ & 6 & Iron-depleted & 123 & 36 \\
\hline 3G03440 & MFS siderophore iron transporter, putative (MirD) & 5.5 & 0.0005 & 2 & Iron-depleted & 96 & 8 \\
\hline 3G03670 & $\begin{array}{l}\text { ABC multidrug transporter with a predicted role in iron metabolism; part of an iron-regulated } \\
\text { gene cluster }\end{array}$ & 5.8 & 0.0003 & 3 & Iron-depleted & 37 & 17 \\
\hline $1 \mathrm{G} 03150$ & C-14 sterol reductase & 9.9 & $8.9 \mathrm{E}-07$ & 1 & Iron-depleted & 34 & 6 \\
\hline $8 G 00440$ & Steroid monooxygenase, putative (EC 1.---.-) & 17.9 & 7.2E-06 & 3 & Iron-depleted & 24 & 12 \\
\hline 7G00580 & Uncharacterized protein & ND & ND & ND & Iron-depleted & 17 & 2 \\
\hline $1 G 14330$ & $\mathrm{ABC}$ transporter, putative & 5.6 & $5.1 \mathrm{E}-07$ & 4 & Iron-depleted & 17 & 17 \\
\hline 3G01400 & ABC multidrug transporter, putative EC 3.6.3.- & 16.3 & $3.6 \mathrm{E}-06$ & 6 & Iron-depleted & 16 & 12 \\
\hline 4G03330 & Plasma membrane stress response protein (Ist2), putative & 4.8 & $4.8 \mathrm{E}-06$ & 3 & Iron-depleted & 15 & 8 \\
\hline $6 G 06620$ & COPII vesicles protein Yip3, putative & 3.3 & 0.002 & 1 & Iron-depleted & 15 & 4 \\
\hline \multicolumn{8}{|c|}{ Uniquely detected in iron-replete samples } \\
\hline 4G09110 & Cytochrome c peroxidase, mitochondrial (CCP) (EC 1.11.1.5) & 45.7 & 8.5E-06 & 1 & Iron-replete & 86 & 13 \\
\hline 3G02270 & Catalase B (EC 1.11.1.6) (Antigenic catalase) & 37.3 & 0.0001 & 4 & Iron-replete & 46 & 17 \\
\hline 2G10580 & Uncharacterized protein & ND & ND & ND & Iron-replete & 34 & 2 \\
\hline $4 \mathrm{G} 11050$ & NADH-ubiquinone oxidoreductase, subunit F, putative (EC 1.6.5.3) & 6.2 & 3.7E-07 & 6 & Iron-replete & 34 & 16 \\
\hline Mt00120 & $\begin{array}{l}\text { Ortholog(s) have cytochrome c oxidase activity, role in aerobic respiration, mitochondrial } \\
\text { electron transport, cytochrome c to oxygen and mitochondrial respiratory chain complex IV } \\
\text { localization }\end{array}$ & ND & ND & ND & Iron-replete & 34 & 4 \\
\hline $5 G 06240$ & Alcohol dehydrogenase, putative (EC 1.1.1.1) & 43.5 & $1.2 \mathrm{E}-05$ & 3 & Iron-replete & 28 & 13 \\
\hline 3G07810 & Succinate dehydrogenase [ubiquinone] flavoprotein subunit, mitochondrial (EC 1.3.5.1) & 23.1 & 2.9E-08 & 4 & Iron-replete & 27 & 13 \\
\hline 2G03730 & Ctr copper transporter family protein & ND & ND & ND & Iron-replete & 27 & 4 \\
\hline 6G04620 & NADH-ubiquinone oxidoreductase B14 subunit, putative (EC 1.6.5.3) & ND & ND & ND & Iron-replete & 25 & 4 \\
\hline 4G08710 & Short chain dehydrogenase, putative & 12.3 & $2.2 \mathrm{E}-05$ & 1 & Iron-replete & 24 & 9 \\
\hline
\end{tabular}

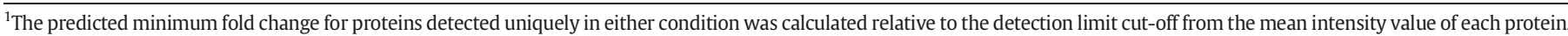

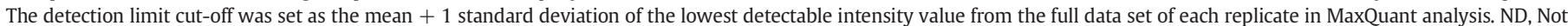
Detected.

Subsequent LFQ comparative proteomic analysis provided a deeper and more informative insight into the iron-responsive microsomal proteome of A. fumigatus. Specifically, based on a combination of quantitative and qualitative analysis (MaxQuant), we have identified a total of 710 microsomal proteins, 96 with increased abundance and 135 with decreased abundance under iron-deplete conditions. Analysis by Progenesis LC-MS also revealed that 16 microsomal proteins underwent $>10$-fold increase in abundance, with SidG (FSC acetyltransferase) levels almost 80 times higher under iron-deplete compared to replete conditions. Conversely, 15 proteins underwent $>10$-fold decrease in abundance, and included a CipC-like protein, the abundance of which reduced by 183 fold under iron-replete conditions. These observations serve to retrospectively expand the interpretation of previous transcriptomic analyses $[29,41]$ by providing additional information on protein localization, and also reveal the dynamic nature of the microsomal proteome in response to altered environmental conditions.

The recovery of siderophore biosynthetic proteins without transmembrane domains in the microsomal fraction may be indicative of the assembly of such proteins at membranes or in membrane bound compartments. Part of the biosynthetic pathway has been shown to be peroxisomally located, however the proteins observed in the microsomal fraction are not amongst these [44]. Co-localisation of siderophore biosynthetic proteins at membranes has been observed in Pseudomonas aeruginosa whereby multi-enzyme complexes directing the synthesis of pyoverdin 1 are formed at the inner membrane in 'siderosomes' $[45,46]$. Assembly of these proteins places pathway intermediates within proximity of the subsequent biosynthetic enzyme thereby increasing biosynthetic efficiency and it is plausible that it occurs in A. fumigatus, however more work is required to validate this.

The genetic regulation of iron homeostasis in A. fumigatus is mediated by the transcription factors, SreA and HapX [3]. Under iron limitation, the bZip factor HapX is activated to induce siderophore biosynthesis and repress iron-consuming pathways. While under iron sufficiency, GATAfactor SreA is activated to repress siderophore biosynthesis. When activated these transcription factors can also function in a negative feedback-loop, whereby HapX represses SreA expression and SreA represses HapX expression [3]. 40 proteins with altered abundance by MaxQuant analysis have also been shown to be transcriptionally regulated by HapX using microarray analysis [41]. This transcriptional analysis was carried out on A. fumigatus shifted from iron-deplete to ironreplete conditions. Despite a different experimental strategy in exposure of A. fumigatus to iron limitation, the microsomal protein analysis supports many of the observed transcriptomic differences. 28 microsomal proteins with decreased abundance under iron limitation were also transcriptionally up-regulated following a switch from irondeplete to iron-replete media, many of which are involved in cellular respiration. For example, out of the 6 genes involved in the TCA cycle negatively regulated by HapX, this analysis has confirmed the decreased abundance of 4 at the protein level during iron limitation (Table S3). One such protein was AcoA (AFUA_6G12930), a transmembrane aconitase involved in the lysine biosynthesis as well as the TCA cycle and containing iron-sulphur binding domains [47]. In addition to genes regulated by HapX, this work has identified an additional 4 proteins involved in the TCA cycle with decreased abundance during iron limitation (Table S3). In total, 50 proteins involved in cellular respiration were shown to have decreased abundance in the microsomal fraction under iron limitation. The repression of the cellular respiration pathway is likely a result of a repression of iron-consuming pathways, as many of the enzymes therein require iron as a cofactor or electron donor. 4 proteins with increased abundance under iron limitation positively regulated by HapX were also observed, including siderophore biosynthetic protein SidG and zinc/cadmium resistance protein (AFUA_2G24570). Similarly, we observed the increased abundance of 9 proteins under 
A
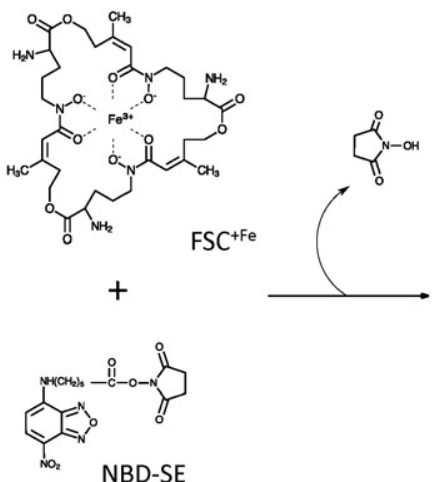

NBD-SE

\section{C}
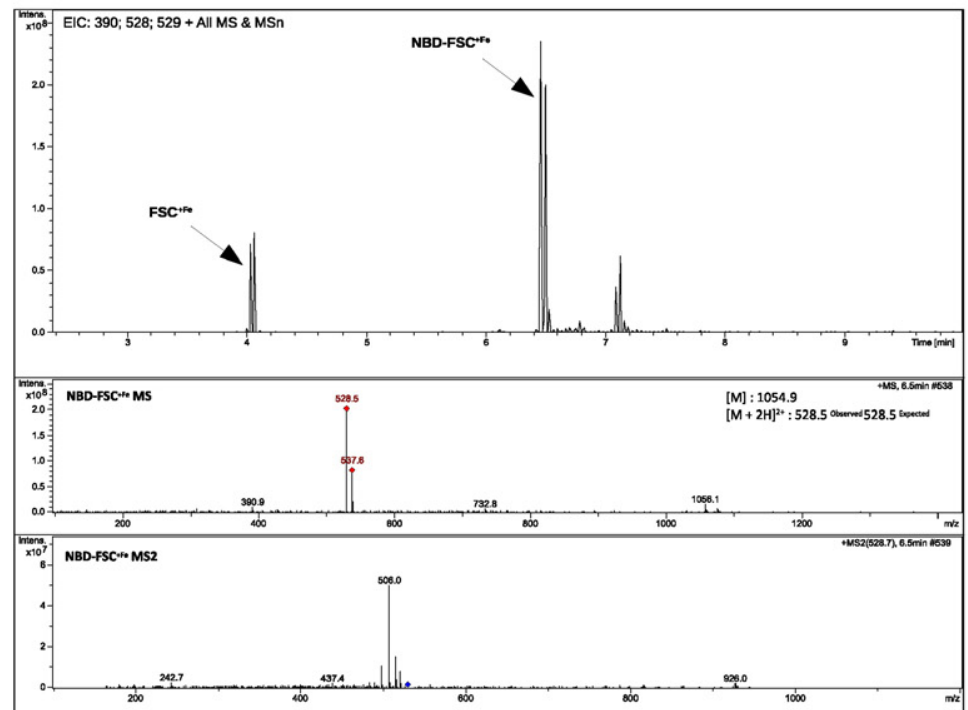

D

$$
\begin{aligned}
& \mathrm{NBD}-\mathrm{FSC}^{+\mathrm{Fe}} \\
& \text { in } \mathrm{MM} \mathrm{Fe}^{-}
\end{aligned}
$$

NBD-FSC ${ }^{+F e}$

in $\mathrm{MM} \mathrm{Fe}^{+}$
B
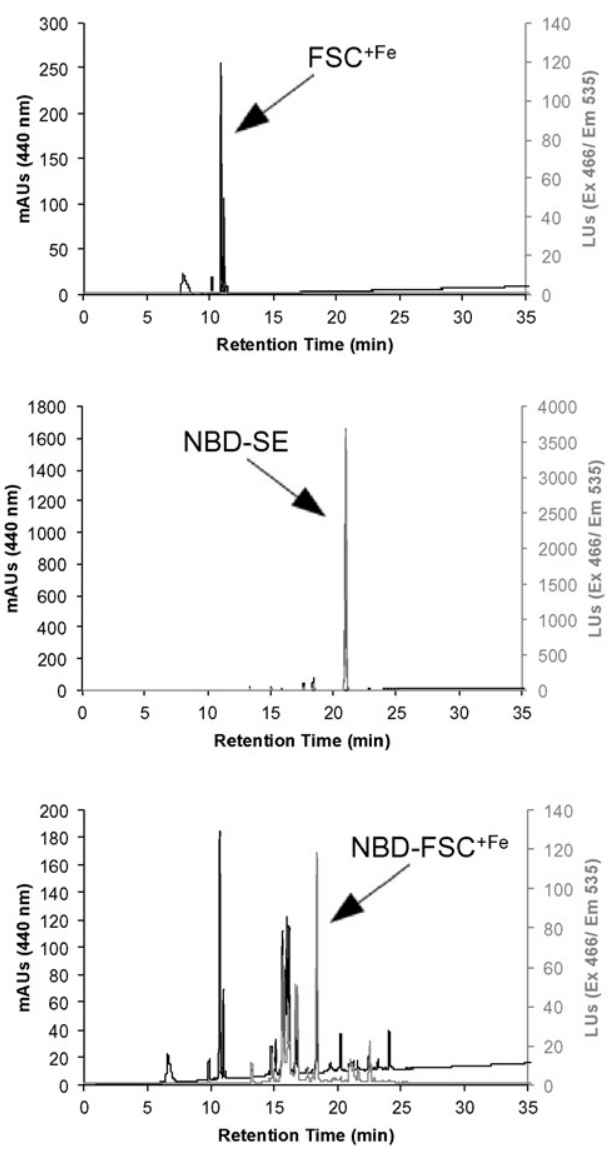

$\mathrm{FSC}^{+\mathrm{Fe}}$

in $\mathrm{MM} \mathrm{Fe}^{-}$

NBD-SE

in $\mathrm{MM} \mathrm{Fe}^{-}$

GFP filter

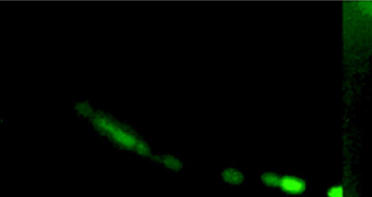

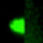

Brightfield

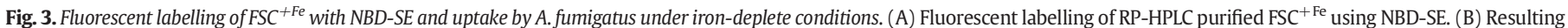

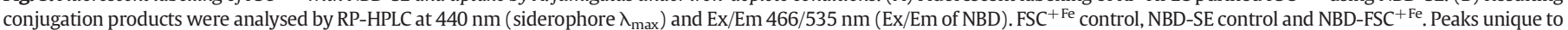

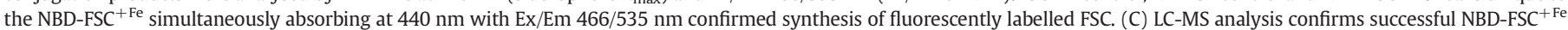

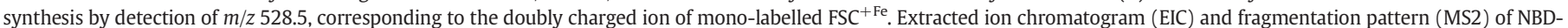

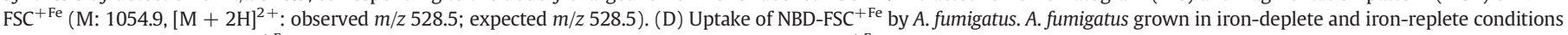

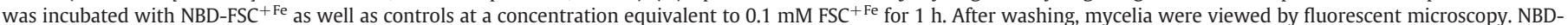
$\mathrm{FSC}^{+\mathrm{Fe}}$ appears to be sequestered and localised to vacuoles during iron-deplete, but not iron-replete growth.

iron limitation which are amongst genes regulated by SreA under iron sufficiency [29], 4 of which included SITs. As shown in Table 2, a combined data analysis approach, utilising both Progenesis LC-MS and
MaxQuant, was necessary to facilitate the quantitation of all siderophore transporters (Sit1, SitT, MirA/C, MirB and MirD), some of which had not previously been identified at the protein level. In addition 
A

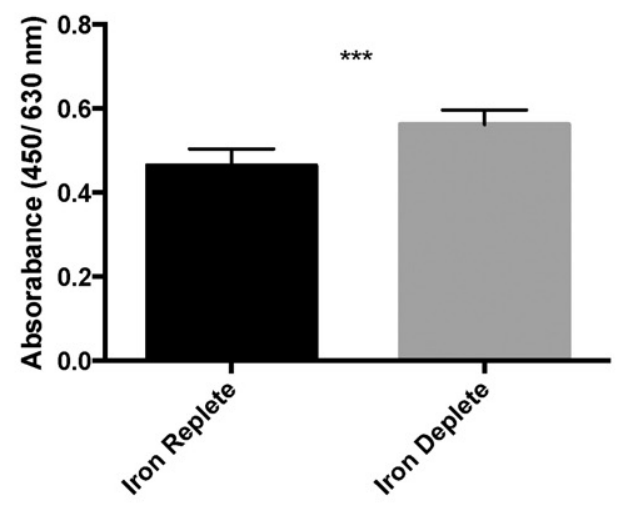

B

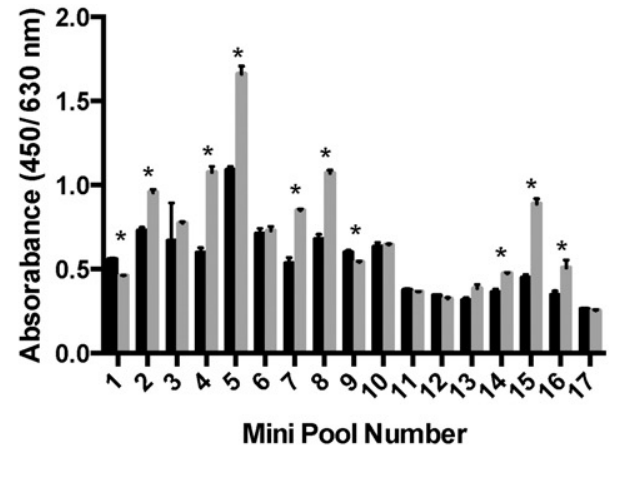

Iron Replete

Iron Deplete

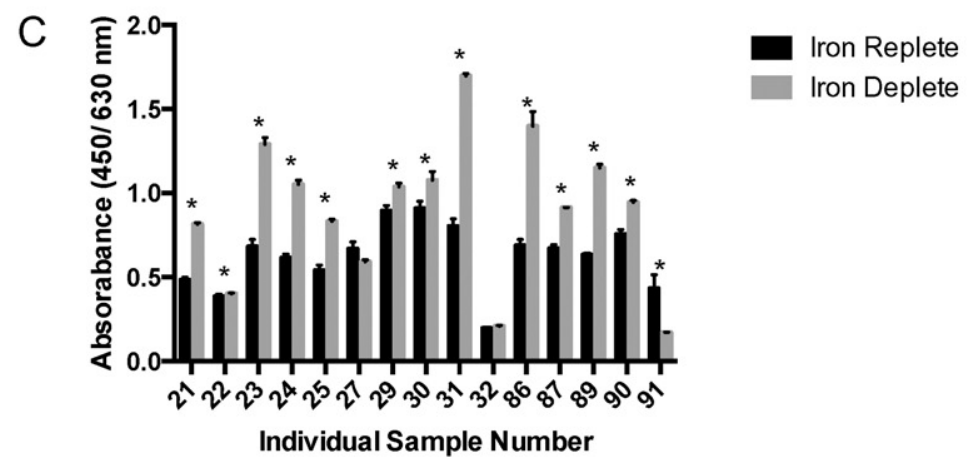

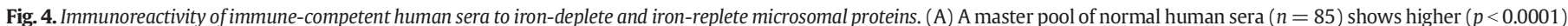

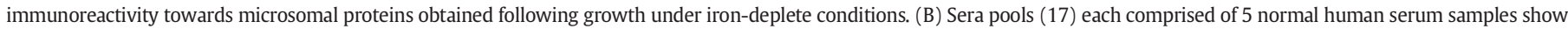

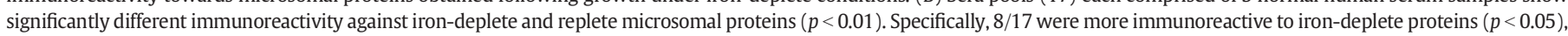

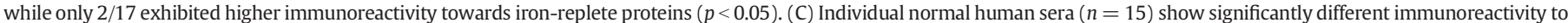
iron-deplete and replete microsomal proteins $(p<0.005)$; $11 / 15$ exhibited greater immunoreactivity to microsomal proteins obtained following iron-deplete growth $(p<0.05)$.

to putative siderophore transporter, SitT, MaxQuant analysis revealed a further 4 ATP-Binding Cassette $(\mathrm{ABC})$ type transporters with increased abundance in response to iron limitation; AFUA_3G03670 which is known to be regulated by HapX and SreA [29,41], a polyketide synthase gene cluster transporter (AFUA_3G01400) [48], AFUA_1G14330 as well as AFUA_5G07970 which has not previously been detected on a protein level or implicated in iron limitation. In addition to SITs observed, one other member of the Major Facilitator Superfamily (MFS) exhibited increased abundance under iron limitation and is a member of the hexadehydroastechrome (HAS) biosynthetic gene cluster, transporter HasB (AFUA_3G12900) [49,50]. Interestingly, putative SIT AFUA_3G13670 was observed to have decreased abundance under iron limitation suggesting it is not directly implicated in the acquisition of iron during starvation.

To explore and validate the biological impact of siderophore uptake following protein induction, we sought a means of visualising siderophore uptake under the experimental conditions used for LFQ proteomics. Related approaches have been achieved in other fungal species using fluorescently labelled hydroxamate type siderophores [42,51,52]; however to the best of our knowledge, this has yet to be successful in A. fumigatus. $\mathrm{FSC}^{+\mathrm{Fe}}$ was purified from A. fumigatus $\Delta$ sidG, deficient in TAFC biosynthesis, and modified with NBD-SE via an amino group to yield fluorescently labelled derivative, NBD-FSC ${ }^{+\mathrm{Fe}}(\mathrm{M}$ : 1054.9, $[\mathrm{M}+2 \mathrm{H}]^{2+}$ : observed $m / z 528.5$; expected $\left.m / z 528.5\right)$, as confirmed by LC-MS and RP-HPLC analysis (Fig. 3). As shown in Fig. 3, NBD$\mathrm{FSC}^{+\mathrm{Fe}}$ is taken up by A. fumigatus during iron-deplete but not ironreplete growth. With the increased expression of putative siderophore transporters as well as other ABC/MFS transporters in iron-deplete conditions, our results suggest that the altered proteomic profile is responsible for this difference in fluorescent siderophore uptake. Interestingly, following uptake, the fluorescent siderophore appears localised in vacuoles within hyphae. The fate of iron following ferri-siderophore uptake and the enzymatic machinery that facilitates its retrieval has been characterised in A. fumigatus [30]. After transport across the membrane via SITs, $\mathrm{FSC}^{+\mathrm{Fe}}$ and $\mathrm{TAFC}^{+\mathrm{Fe}}$ are hydrolysed in the cytosol by SidJ and EstB, respectively, to yield degradation products still capable of chelating iron. Iron is then transferred to intracellular siderophore FC, vacuolar storage or metabolism prior to the recycling of degradation products [11-13]. While part of siderophore biosynthetic pathway has been shown to occur peroxisomally [44], to the best of our knowledge there has been no evidence that following re-uptake ferrisiderophores or their cognate degradation products can localise to vacuoles in A. fumigatus. Whether the fluorescence we observed is generated by intact $\mathrm{NBD}-\mathrm{FSC}^{+\mathrm{Fe}}$ or degradation products remains to be elucidated; however, there is evidence to suggest at least part of the processing pathway following siderophore re-uptake is localised to vacuoles.

Recently, siderophore capacity for metal ion chelation has been exploited for various in vivo applications highlighting the utility of these naturally occurring non-ribosomal peptides [53-55,59]. For example, using a radiotracer strategy to improve diagnosis of $A$. fumigatus infection, ${ }^{68} \mathrm{Ga}-\mathrm{TAFC}$ has been deployed for in vivo imaging of invasive aspergillosis $[56,59,60]$. In addition to facilitating early diagnosis, there is an increasingly appealing candidacy of siderophores as drug targets due to their importance during infection [18]. Using a 'Trojan Horse' approach, modification of the siderophore with an anti-fungal can enhance the antifungal's efficacy by facilitating uptake [57,61]. Evidence for the efficacy of this strategy has emerged in Candida species and bacteria including P. aeruginosa and Staphylococcus aureus [58,62-64]; however it has yet to be realised in A. fumigatus. Our findings regarding 
fluorescent FSC uptake by A. fumigatus suggest the potential of derivatized FSC as a 'Trojan Horse' to target and enhance uptake of anti-fungal drugs into A. fumigatus.

Proteomic analysis of A. fumigatus mycelial and secreted proteins grown on different substrates relevant to the host as well as immunoproteomic analysis using IA patient serum has revealed insight into the phenotype of $A$. fumigatus during infection [25,65-67]. However, iron limitation has yet to be similarly investigated, yet represents an important environmental factor within the host and, as we have shown, significantly alters the phenotype of the organism. Herein, the relevance of microsomal proteins expressed under iron limitation to immunological detection during interaction with humans was investigated using an indirect ELISA. Microsomal proteins from iron-deplete and replete growth were coated onto ELISA plates, to which immune-competent human serum was added. Aspergillus-specific IgG reactivity in sera was measured by detection with a secondary anti-human IgG-HRP conjugate. Results indicated that in a master pool of 85 sera, there was significantly $(p<0.0001)$ higher IgG reactivity against microsomal proteins expressed in iron-deplete growth (Fig. 4). The constituent sera were divided into 17 smaller pools of 5 samples and re-analysed. 8/17 samples exhibited higher immunoreactivity against iron-deplete proteins, while only 2 exhibited higher immunoreactivity against iron-replete proteins $(p<0.05)$ (Fig. 4). The constituent individual sera $(n=15)$ of the pools with the highest levels of immunoreactivity against iron-deplete proteins were then analysed and showed significantly different immunoreactivity to iron-deplete and replete microsomal proteins $(p<0.005)$. Sera $(11 / 15)$ exhibited greater immunoreactivity to microsomal proteins obtained following iron-deplete growth $(p<0.05)$ (Fig. 4). The importance of the iron-deplete phenotype of $A$. fumigatus during infection is demonstrated by the essentiality of siderophore-mediated iron acquisition to virulence and the transcriptional up-regulation of cognate genes in vivo $[5,6,68]$. Up-regulated transcripts overlapping with proteins induced under iron limitation include siderophore transporters, MirB, MirD and Sit1 [68]. Recently, RNA-seq analysis of A. fumigatus grown in blood, identified genes with increased transcription including siderophore biosynthetic enzymes, SidA and SidD as well as transporters MirB, MirD, Sit1 and SitT, also observed herein under iron limitation [69]. Together, these results indicate that a suite of new microsomal proteins may be expressed upon encountering the ironlimited host environment. Moreover, these results suggest that the transporters with potential utilisation via the 'Trojan Horse' therapeutic strategy may be expressed in the host during infection and therefore warrant further investigation.

The importance of high affinity iron acquisition strategies to the pathogenicity of A. fumigatus has been well defined $[5,6,68]$. Strict regulation of these strategies represents an integral mechanism of cellular homeostatic maintenance to avoid generation of deleterious ROS [70]. Proteomic analyses carried out herein indicate significant and functional microsomal proteome remodelling under iron limitation. Under the conditions investigated we have confirmed siderophore biosynthesis and uptake to be intact, thereby validating the relevance of the induced proteins during high affinity iron acquisition. In addition, this induced proteome increased host recognition, which along with existing knowledge highlights the contextual importance of iron at the interface of infection. Thus, lending further support to the rationale of targeting siderophore-mediated iron acquisition in vivo as a therapeutic strategy. Furthermore, the uptake of modified FSC indicates a practical validity to the use of modified siderophores as anti-fungals in a 'Trojan Horse' strategy specifically against A. fumigatus. Ultimately this work has revealed novel components of siderophore uptake and processing as well as further insight into the network of proteins affected by iron limitation. Moreover, by identifying specific relevant proteins and a successful analogue strategy this work has commenced the practical realisation of targeting iron acquisition strategies via a 'Trojan Horse' therapy against $A$. fumigatus. The importance of iron acquisition strategies to the virulence of various important pathogens has been well demonstrated [2]. The methodology presented herein provides a rationale with potential to reveal iron acquisition strategies and expose antimicrobial targets in other important microbial pathogens.

Supplementary data to this article can be found online at http://dx. doi.org/10.1016/j.jprot.2015.12.025.

\section{Transparency Document}

The Transparency document associated with this article can be found, in online version.

\section{Acknowledgements}

This work was funded by a Science Foundation Ireland Principal Investigator Award to SD (12/IP/1695). RAO was funded by a 3U Partnership Award (DCU/NUIM/RCSI). SKD was a recipient of Irish Research Council Embark PhD Fellowships. LC-MS facilities were funded by competitive awards from the Irish Higher Education Authority.

\section{References}

[1] B. Halliwell, J.M. Gutteridge, Oxygen toxicity, oxygen radicals, transition metals and disease, Biochem. J. 219 (1984) 1-14.

[2] J.E. Cassat, E.P. Skaar, Iron in infection and immunity, Cell Host Microbe 13 (2013) 509-519, http://dx.doi.org/10.1016/j.chom.2013.04.010.

[3] H. Haas, Iron - a key nexus in the virulence of Aspergillus fumigatus, Front. Microbiol. 3 (2012) 28, http://dx.doi.org/10.3389/fmicb.2012.00028.

[4] T.R.T. Dagenais, N.P. Keller, Pathogenesis of Aspergillus fumigatus in invasive aspergillosis, Clin. Microbiol. Rev. 22 (2009) 447-465, http://dx.doi.org/10.1128/CMR. 00055-08.

[5] M. Schrettl, E. Bignell, C. Kragl, C. Joechl, T. Rogers, H.N. Arst, et al., Siderophore biosynthesis but not reductive iron assimilation is essential for Aspergillus fumigatus virulence, J. Exp. Med. 200 (2004) 1213-1219, http://dx.doi.org/10.1084/jem. 20041242.

[6] A.H.T. Hissen, A.N.C. Wan, M.L. Warwas, L.J. Pinto, M.M. Moore, The Aspergillus fumigatus siderophore biosynthetic gene sidA, encoding L-ornithine N5-oxygenase, is required for virulence, Infect. Immun. 73 (2005) 5493-5503, http://dx.doi.org/ 10.1128/IAI.73.9.5493-5503.2005

[7] A.H.T. Hissen, J.M.T. Chow, L.J. Pinto, M.M. Moore, Survival of Aspergillus fumigatus in serum involves removal of iron from transferrin: the role of siderophores, Infect. Immun. 72 (2004) 1402-1408.

[8] M. Schrettl, E. Bignell, C. Kragl, Y. Sabiha, O. Loss, M. Eisendle, et al., Distinct roles for intra- and extracellular siderophores during Aspergillus fumigatus infection, PLoS Pathog. 3 (2007) 1195-1207, http://dx.doi.org/10.1371/journal.ppat.0030128.

[9] H. Haas, M. Schoeser, E. Lesuisse, J.F. Ernst, W. Parson, B. Abt, et al., Characterization of the Aspergillus nidulans transporters for the siderophores enterobactin and triacetylfusarinine C, Biochem. J. 371 (2003) 505-513, http://dx.doi.org/10.1042/ bj20021685.

[10] C.C. Philpott, O. Protchenko, Response to iron deprivation in Saccharomyces cerevisiae, Eukaryot. Cell 7 (2008) 20-27, http://dx.doi.org/10.1128/EC.00354-07.

[11] C. Kragl, M. Schrettl, B. Abt, B. Sarg, H.H. Lindner, H. Haas, EstB-mediated hydrolysis of the siderophore triacetylfusarinine $\mathrm{C}$ optimizes iron uptake of Aspergillus fumigatus, Eukaryot. Cell 6 (2007) 1278-1285, http://dx.doi.org/10.1128/EC. 00066-07.

[12] F. Gsaller, M. Eisendle, B.E. Lechner, M. Schrettl, H. Lindner, D. Müller, et al., The interplay between vacuolar and siderophore-mediated iron storage in Aspergillus fumigatus, Metallomics 4 (2012) 1262-1270, http://dx.doi.org/10.1039/ c2mt20179h.

[13] M. Gründlinger, F. Gsaller, M. Schrettl, H. Lindner, H. Haas, Aspergillus fumigatus SidJ mediates intracellular siderophore hydrolysis, Appl. Environ. Microbiol. 79 (2013) 7534-7536, http://dx.doi.org/10.1128/AEM.01285-13.

[14] H. Haas, M. Eisendle, B.G. Turgeon, Siderophores in fungal physiology and virulence, Annu. Rev. Phytopathol. 46 (2008) 149-187, http://dx.doi.org/10.1146/annurev. phyto.45.062806.094338.

[15] S.S. Pao, I.T. Paulsen, M.H.J. Saier, Major facilitator superfamily, Microbiol. Mol. Biol. Rev. 62 (1998) 1-34

[16] M.H. Saier, J.T. Beatty, A. Goffeau, K.T. Harley, W.H. Heijne, S.C. Huang, et al., The major facilitator superfamily, J. Mol. Microbiol. Biotechnol. 1 (1999) 257-279.

[17] E. Lesuisse, P.L. Blaiseau, A. Dancis, J.M. Camadro, Siderophore uptake and use by the yeast Saccharomyces cerevisiae, Microbiology 147 (2001) 289-298.

[18] A.L. Lamb, Breaking a pathogen's iron will: inhibiting siderophore production as an antimicrobial strategy, Biochim. Biophys. Acta 1854 (2015) 1054-1070, http://dx. doi.org/10.1016/j.bbapap.2015.05.001.

[19] O. Kniemeyer, F. Lessing, O. Scheibner, C. Hertweck, A.A. Brakhage, Optimisation of a 2-D gel electrophoresis protocol for the human-pathogenic fungus Aspergillus fumigatus, Curr. Genet. 49 (2006) 178-189, http://dx.doi.org/10.1007/s00294-0050047-9.

[20] S. Carberry, C.M. Neville, K. Kavanagh, S. Doyle, Analysis of major intracellular proteins of Aspergillus fumigatus by MALDI mass spectrometry: identification and 
characterisation of an elongation factor $1 \mathrm{~B}$ protein with glutathione transferase activity, Biochem. Biophys. Res. Commun. 341 (2006) 1096-1104, http://dx.doi.org/ 10.1016/j.bbrc.2006.01.078.

[21] A.R. Asif, M. Oellerich, V.W. Amstrong, B. Riemenschneider, M. Monod, U. Reichard, Proteome of conidial surface associated proteins of Aspergillus fumigatus reflecting potential vaccine candidates and allergens, J. Proteome Res. 5 (2006) 954-962, http://dx.doi.org/10.1021/pr0504586.

[22] M. Vödisch, D. Albrecht, F. Lessing, A.D. Schmidt, R. Winkler, R. Guthke, et al., Twodimensional proteome reference maps for the human pathogenic filamentous fungus Aspergillus fumigatus, Proteomics 9 (2009) 1407-1415, http://dx.doi.org/10. 1002/pmic.200800394.

[23] J. Teutschbein, D. Albrecht, M. Pötsch, R. Guthke, V. Aimanianda, C. Clavaud, et al., Proteome profiling and functional classification of intracellular proteins from conidia of the human-pathogenic mold Aspergillus fumigatus, J. Proteome Res. 9 (2010) 3427-3442, http://dx.doi.org/10.1021/pr9010684.

[24] M. Vödisch, K. Scherlach, R. Winkler, C. Hertweck, H.-P. Braun, M. Roth, et al., Analysis of the Aspergillus fumigatus proteome reveals metabolic changes and the activation of the pseurotin A biosynthesis gene cluster in response to hypoxia, J. Proteome Res. 10 (2011) 2508-2524, http://dx.doi.org/10.1021/ pr1012812.

[25] D. Wartenberg, K. Lapp, I.D. Jacobsen, H.-M. Dahse, O. Kniemeyer, T. Heinekamp, et al., Secretome analysis of Aspergillus fumigatus reveals Asp-hemolysin as a major secreted protein, Int. J. Med. Microbiol. 301 (2011) 602-611, http://dx.doi. org/10.1016/j.ijmm.2011.04.016.

[26] S.E. Cagas, M.R. Jain, H. Li, D.S. Perlin, The proteomic signature of Aspergillus fumigatus during early development, Mol. Cell. Proteomics 10 (2011)http://dx.doi. org/10.1074/mcp.M111.010108 (M111.010108).

[27] M.-J. Suh, N.D. Fedorova, S.E. Cagas, S. Hastings, R.D. Fleischmann, S.N. Peterson, et al., Development stage-specific proteomic profiling uncovers small, lineage specific proteins most abundant in the Aspergillus fumigatus conidial proteome, Proteome Sci. 10 (2012) 30, http://dx.doi.org/10.1186/1477-5956-10-30.

[28] R.A. Owens, S. Hammel, K.J. Sheridan, G.W. Jones, S. Doyle, A proteomic approach to investigating gene cluster expression and secondary metabolite functionality in Aspergillus fumigatus, PLoS One 9 (2014) e106942, http://dx.doi.org/10.1371/journal. pone.0106942.

[29] M. Schrettl, H.S. Kim, M. Eisendle, C. Kragl, W.C. Nierman, T. Heinekamp, et al., SreAmediated iron regulation in Aspergillus fumigatus, Mol. Microbiol. 70 (2008) 27-43, http://dx.doi.org/10.1111/j.1365-2958.2008.06376.x.

[30] H. Haas, Fungal siderophore metabolism with a focus on Aspergillus fumigatus, Nat. Prod. Rep. 31 (2014) 1266-1276, http://dx.doi.org/10.1039/c4np00071d.

[31] O. Kniemeyer, A.D. Schmidt, M. Vödisch, D. Wartenberg, A.A. Brakhage, Identification of virulence determinants of the human pathogenic fungi Aspergillus fumigatus and Candida albicans by proteomics, Int. J. Med. Microbiol. 301 (2011) 368-377, http://dx.doi.org/10.1016/j.ijmm.2011.04.001.

[32] H. Ouyang, Y. Luo, L. Zhang, Y. Li, C. Jin, Proteome analysis of Aspergillus fumigatus total membrane proteins identifies proteins associated with the glycoconjugates and cell wall biosynthesis using 2D LC-MS/MS, Mol. Biotechnol. 44 (2010) 177-189, http://dx.doi.org/10.1007/s12033-009-9224-2.

[33] G. Pontecorvo, J.A. Roper, L.M. Hemmons, K.D. MacDonald, A.W.J. Bufton, The genetics of Aspergillus nidulans, Adv. Genet. 5 (1953) 141-238.

[34] A. Shevchenko, H. Tomas, J. Havlis, J.V. Olsen, M. Mann, In-gel digestion for mass spectrometric characterization of proteins and proteomes, Nat. Protoc. 1 (2007) 2856-2860.

[35] R.A. Owens, G. O'Keeffe, E.B. Smith, S.K. Dolan, S. Hammel, K.J. Sheridan, et al., Interplay between gliotoxin resistance, secretion, and the methyl/methionine cycle in Aspergillus fumigatus, Eukaryot. Cell 14 (2015) 941-957, http://dx.doi.org/10.1128/EC. 00055-15.

[36] S.K. Dolan, R.A. Owens, G. O'Keeffe, S. Hammel, D.A. Fitzpatrick, G.W. Jones, et al., Regulation of nonribosomal peptide synthesis: bis-thiomethylation attenuates gliotoxin biosynthesis in Aspergillus fumigatus, Chem. Biol. 21 (2014) 999-1012, http://dx.doi.org/10.1016/j.chembiol.2014.07.006.

[37] G. O'Keeffe, S. Hammel, R.A. Owens, T.M. Keane, D.A. Fitzpatrick, G.W. Jones, et al., RNA-seq reveals the pan-transcriptomic impact of attenuating the gliotoxin selfprotection mechanism in Aspergillus fumigatus, BMC Genomics 15 (2014) 894, http://dx.doi.org/10.1186/1471-2164-15-894.

[38] C. Collins, T.M. Keane, D.J. Turner, G. O'Keeffe, D.A. Fitzpatrick, S. Doyle, Genomic and proteomic dissection of the ubiquitous plant pathogen, Armillaria mellea: toward a new infection model system, J. Proteome Res. 12 (2013) 2552-2570, http://dx.doi. org/10.1021/pr301131t.

[39] P. Meleady, M. Gallagher, C. Clarke, M. Henry, N. Sanchez, N. Barron, et al., Impact of miR-7 over-expression on the proteome of Chinese hamster ovary cells, J. Biotechnol. 160 (2012) 251-262, http://dx.doi.org/10.1016/j.jbiotec.2012.03. 002.

[40] S. Priebe, J. Linde, D. Albrecht, R. Guthke, A.A. Brakhage, FungiFun: a web-based application for functional categorization of fungal genes and proteins, Fungal Genet. Biol. 48 (2011) 353-358.

[41] M. Schrettl, N. Beckmann, J. Varga, T. Heinekamp, I.D. Jacobsen, C. Jöchl, et al., HapX-mediated adaption to iron starvation is crucial for virulence of Aspergillus fumigatus, PLoS Pathog. 6 (2010) e1001124, http://dx.doi.org/10.1371/journal. ppat.1001124.

[42] M. Froissard, N. Belgareh-Touzé, M. Dias, N. Buisson, J.-M. Camadro, R. HaguenauerTsapis, et al., Trafficking of siderophore transporters in Saccharomyces cerevisiae and intracellular fate of ferrioxamine B conjugates, Traffic 8 (2007) 1601-1616, http:// dx.doi.org/10.1111/j.1600-0854.2007.00627.x.

[43] I. Raymond-Bouchard, C.S. Carroll, J.R. Nesbitt, K.a. Henry, L.J. Pinto, M. Moinzadeh, et al., Structural requirements for the activity of the MirB ferrisiderophore transporter of Aspergillus fumigatus, Eukaryot. Cell 11 (2012) 1333-1344, http:// dx.doi.org/10.1128/EC.00159-12.

[44] M. Gründlinger, S. Yasmin, B.E. Lechner, S. Geley, M. Schrettl, M. Hynes, et al., Fungal siderophore biosynthesis is partially localized in peroxisomes, Mol. Microbiol. 88 (2013) 862-875, http://dx.doi.org/10.1111/mmi.12225.

[45] F. Imperi, P. Visca, Subcellular localization of the pyoverdine biogenesis machinery of Pseudomonas aeruginosa: a membrane-associated "siderosome.", FEBS Lett. 587 (2013) 3387-3391, http://dx.doi.org/10.1016/j.febslet.2013.08.039.

[46] V. Gasser, L. Guillon, O. Cunrath, I.J. Schalk, Cellular organization of siderophore biosynthesis in Pseudomonas aeruginosa: evidence for siderosomes, J. Inorg. Biochem. 148 (2015) 27-34, http://dx.doi.org/10.1016/j.jinorgbio.2015.01.017.

[47] F. Fazius, E. Shelest, P. Gebhardt, M. Brock, The fungal $\alpha$-aminoadipate pathway for lysine biosynthesis requires two enzymes of the aconitase family for the isomerization of homocitrate to homoisocitrate, Mol. Microbiol. 86 (2012) 1508-1530, http:// dx.doi.org/10.1111/mmi.12076.

[48] D.O. Inglis, J. Binkley, M.S. Skrzypek, M.B. Arnaud, G.C. Cerqueira, P. Shah, et al., Comprehensive annotation of secondary metabolite biosynthetic genes and gene clusters of Aspergillus nidulans, A. fumigatus, A. niger and A. oryzae, BMC Microbiol. 13 (2013) 91, http://dx.doi.org/10.1186/1471-2180-13-91.

[49] W.-B. Yin, J.a. Baccile, J.W. Bok, Y. Chen, N.P. Keller, F.C. Schroeder, A nonribosoma peptide synthetase-derived iron(III) complex from the pathogenic fungus Aspergillus fumigatus, J. Am. Chem. Soc. 135 (2013) 2064-2067, http://dx.doi.org/10.1021/ ja311145n.

[50] P. Wiemann, B.E. Lechner, J.A. Baccile, T.A. Velk, W.-B. Yin, J.W. Bok, et al., Perturbations in small molecule synthesis uncovers an iron-responsive secondary metabolite network in Aspergillus fumigatus, Front. Microbiol. 5 (2014) 530, http://dx.doi.org 10.3389/fmicb.2014.00530.

[51] O. Ardon, R. Nudelman, C. Caris, J. Libman, A. Shanzer, Y. Chen, et al., Iron uptake in Ustilago maydis: tracking the iron path. J. Bacteriol. 180 (1998) 2021-2026.

[52] H. Ouchetto, M. Dias, R. Mornet, E. Lesuisse, J.-M. Camadro, A new route to trihydroxamate-containing artificial siderophores and synthesis of a new fluorescent probe, Bioorg. Med. Chem. 13 (2005) 1799-1803, http://dx.doi.org/10.1016/j. bmc.2004.11.053.

[53] P.A. Knetsch, C. Zhai, C. Rangger, M. Blatzer, H. Haas, P. Kaeopookum, et al., [(68)Ga]FSC-(RGD) 3 a trimeric RGD peptide for imaging $\alpha v \beta 3$ integrin expression based on a novel siderophore derived chelating scaffold-synthesis and evaluation, Nucl. Med. Biol. 42 (2015) 115-122, http://dx.doi.org/10.1016/j.nucmedbio.2014. 10.001.

[54] C. Zhai, D. Summer, C. Rangger, H. Haas, R. Haubner, C. Decristoforo, Fusarinine $C$, a novel siderophore-based bifunctional chelator for radiolabeling with gallium-68, J. Label. Compd. Radiopharm. (2015)http://dx.doi.org/10.1002/jlcr. 3286.

[55] M. Petrik, H. Haas, G. Dobrozemsky, C. Lass-Flörl, A. Helbok, M. Blatzer, et al., 68Gasiderophores for PET imaging of invasive pulmonary aspergillosis: proof of principle, J. Nucl. Med. 51 (2010) 639-645, http://dx.doi.org/10.2967/jnumed. 109.072462.

[56] M. Petrik, G.M. Franssen, H. Haas, P. Laverman, C. Hörtnagl, M. Schrettl, et al., Preclinical evaluation of two 68Ga-siderophores as potential radiopharmaceuticals for Aspergillus fumigatus infection imaging, Eur. J. Nucl. Med. Mol. Imaging 39 (2012) 1175-1183, http://dx.doi.org/10.1007/s00259-012-2110-3.

[57] M. Miethke, M.A. Marahiel, Siderophore-based iron acquisition and pathogen control, Microbiol. Mol. Biol. Rev. 71 (2007) 413-451, http://dx.doi.org/10.1128/ MMBR.00012-07.

[58] U. Möllmann, L. Heinisch, A. Bauernfeind, T. Köhler, D. Ankel-Fuchs, Siderophores as drug delivery agents: application of the "Trojan Horse" strategy, Biometals 22 (2009) 615-624, http://dx.doi.org/10.1007/s10534-009-9219-2.

[59] H. Haas, M. Petrik, C. Decristoforo, An iron-mimicking, trojan horse-entering fungihas the time come for molecular imaging of fungal infections? PLoS Pathog. 11 (2015) e1004568, http://dx.doi.org/10.1371/journal.ppat.1004568.

[60] M. Petrik, H. Haas, A. Helbok, M. Blatzer, M. Schrettl, C. Lass-Floerl, et al., Comparison of 68Ga-siderophores for imaging Aspergillus fumigatus infections with PET, Nucl. Med. Biol. 37 (2010) 726, http://dx.doi.org/10.1016/j.nucmedbio. 2010.04.116

[61] M.J. Miller, H. Zhu, Y. Xu, C. Wu, A.J. Walz, A. Vergne, et al., Utilization of microbial iron assimilation processes for the development of new antibiotics and inspiration for the design of new anticancer agents, Biometals 22 (2009) 61-75, http://dx.doi. org/10.1007/s10534-008-9185-0.

[62] G. Bernier, V. Girijavallabhan, A. Murray, N. Niyaz, P. Ding, M.J. Miller, et al., Desketoneoenactin-siderophore conjugates for candida: evidence of iron transport-dependent species selectivity, Antimicrob. Agents Chemother. 49 (2005) 241-248, http://dx.doi.org/10.1128/AAC.49.1.241-248.2005.

[63] S.J. Milner, A. Seve, A.M. Snelling, G.H. Thomas, K.G. Kerr, A. Routledge, et al., Staphyloferrin a as siderophore-component in fluoroquinolone-based trojan horse antibiotics, Org. Biomol. Chem. 11 (2013) 3461-3468, http://dx.doi.org/10.1039/ c3ob40162f.

[64] D. Landman, M. Singh, B. El-Imad, E. Miller, T. Win, J. Quale, In vitro activity of the siderophore monosulfactam BAL30072 against contemporary Gram-negative pathogens from New York City, including multidrug-resistant isolates, Int. J. Antimicrob. Agents 43 (2014) 527-532, http://dx.doi.org/10.1016/j.jjantimicag.2014.02.017.

[65] A. Kumar, R. Ahmed, P.K. Singh, P.K. Shukla, Identification of virulence factors and diagnostic markers using immunosecretome of Aspergillus fumigatus, J. Proteome 74 (2011) 1104-1112, http://dx.doi.org/10.1016/j.jprot.2011.04.004.

[66] S.K. Upadhyay, P. Gautam, H. Pandit, Y. Singh, S.F. Basir, T. Madan, Identification of fibrinogen-binding proteins of Aspergillus fumigatus using proteomic approach, Mycopathologia 173 (2012) 73-82, http://dx.doi.org/10.1007/s11046011-9465-z. 
[67] L. Shi, F. Li, M. Huang, J. Lu, X. Kong, S. Wang, et al., Immunoproteomics based identification of thioredoxin reductase GliT and novel Aspergillus fumigatus antigens for serologic diagnosis of invasive aspergillosis, BMC Microbiol. 12 (2012) 11, http:// dx.doi.org/10.1186/1471-2180-12-11.

[68] A. McDonagh, N.D. Fedorova, J. Crabtree, Y. Yu, S. Kim, D. Chen, et al., Sub-telomere directed gene expression during initiation of invasive aspergillosis, PLoS Pathog. 4 (2008) e1000154, http://dx.doi.org/10.1371/journal.ppat.1000154.
[69] H. Irmer, S. Tarazona, C. Sasse, P. Olbermann, J. Loeffler, S. Krappmann, et al., RNAseq analysis of Aspergillus fumigatus in blood reveals a just wait and see resting stage behavior, BMC Genomics 16 (2015) 640, http://dx.doi.org/10. 1186/s12864-015-1853-1.

[70] M. Brandon, B. Howard, C. Lawrence, R. Laubenbacher, Iron acquisition and oxidative stress response in Aspergillus fumigatus, BMC Syst. Biol. 9 (2015) 19, http://dx. doi.org/10.1186/s12918-015-0163-1. 